IZA DP No. 7785

Job Lock:

Evidence from a Regression Discontinuity Design

Robert W. Fairlie

Kanika Kapur

Susan Gates

November 2013 


\title{
Job Lock: Evidence from a Regression Discontinuity Design
}

\author{
Robert W. Fairlie \\ University of California, Santa Cruz, \\ RAND and IZA \\ Kanika Kapur \\ University College Dublin \\ Susan Gates \\ RAND
}
Discussion Paper No. 7785
November 2013

\author{
IZA \\ P.O. Box 7240 \\ 53072 Bonn \\ Germany \\ Phone: +49-228-3894-0 \\ Fax: +49-228-3894-180 \\ E-mail: iza@iza.org
}

Any opinions expressed here are those of the author(s) and not those of IZA. Research published in this series may include views on policy, but the institute itself takes no institutional policy positions. The IZA research network is committed to the IZA Guiding Principles of Research Integrity.

The Institute for the Study of Labor (IZA) in Bonn is a local and virtual international research center and a place of communication between science, politics and business. IZA is an independent nonprofit organization supported by Deutsche Post Foundation. The center is associated with the University of Bonn and offers a stimulating research environment through its international network, workshops and conferences, data service, project support, research visits and doctoral program. IZA engages in (i) original and internationally competitive research in all fields of labor economics, (ii) development of policy concepts, and (iii) dissemination of research results and concepts to the interested public.

IZA Discussion Papers often represent preliminary work and are circulated to encourage discussion. Citation of such a paper should account for its provisional character. A revised version may be available directly from the author. 
IZA Discussion Paper No. 7785

November 2013

\section{ABSTRACT}

\section{Job Lock: Evidence from a Regression Discontinuity Design}

Employer-provided health insurance may restrict job mobility, resulting in "job lock." Previous research on job lock finds mixed results using several methodologies. We take a new approach to examine job-lock by exploiting the discontinuity created at age 65 through the qualification for Medicare. Using a novel procedure for identifying age in months from matched monthly CPS data and a relatively unexplored administration measure of job mobility, we compare job mobility among male workers in the months just prior to turning age 65 to job mobility in the months just after turning age 65 . We find no evidence that job mobility increases at the age 65 threshold when Medicare eligibility starts. We also do not find evidence that other factors such as retirement, reduction in hours worked, social security eligibility, pension eligibility, and sample changes confound the results on job mobility in the month individuals turn 65.

JEL Classification: J60, I13

Keywords: $\quad$ job lock, health insurance, Medicare

Corresponding author:

Robert W. Fairlie

Department of Economics

University of California, Santa Cruz

1156 High St

Santa Cruz, CA 95064

USA

E-mail: rfairlie@ucsc.edu

\footnotetext{
* This research was supported by the Kauffman-RAND Institute for Entrepreneurship Public Policy through a grant from the Ewing Marion Kauffman Foundation. We thank David Card, Jonathan Leonard, Ken Couch, Elise Atkins, Paul Devereux, Alex Resch and seminar participants at UC Berkeley, UCSC, and the ASHE Meetings for useful comments and suggestions.
} 


\section{Introduction}

The predominant source of health insurance in the United States for working-age adults is employer-provided health insurance. Over three-quarters of full-time workers between the ages of 18 and 64 have health insurance through employers. In comparison, only 6 percent have health insurance purchased through the individual market and another 6 percent have public insurance (Fronstin 2010). A potential cost of this reliance on employer-provided health insurance is the non-portability of insurance across employers that potentially results in "job lock." Workers may be reluctant to leave their jobs to search for new ones when otherwise optimal because of the possible loss of coverage due to pre-existing condition exclusions, waiting periods on new jobs, loss of particular insurance plans, and disruption in the continuity of care with their healthcare providers. ${ }^{1}$ Changing jobs during a health plan year may also result in the loss of any earned credit towards plan deductibles and unused balances in health reimbursement accounts. The heavily-debated Affordable Care Act (ACA) of 2010 attempts to increase coverage and portability of health insurance with key provisions coming into force in 2014.

Although the theoretical justifications for the existence of job lock are unambiguous, there is no consensus in the large and growing empirical literature on the size of job lock (Gruber and Madrian 2004). A number of studies find large and statistically significant estimates of job lock, often finding that health insurance reduces

\footnotetext{
${ }^{1}$ Federal regulations (HIPAA and COBRA) aim to reduce these problems; however, individuals still have to either pay for potentially expensive continuation coverage if they terminate employment or face new preexisting condition exclusions and waiting periods if they are uninsured for more than 63 days between jobs. COBRA is expensive with premiums averaged $\$ 4,824$ for employee-only coverage and $\$ 13,375$ for family coverage in 2009, and this expense may be responsible for low take-up rates of less than 10 percent (Fronstin, 2010). Take-up rates increased when legislation allowed for a temporary COBRA subsidy from 2009 to 2010, however, this subsidy has now expired (Bovbjerg et al. 2009).
} 
job mobility by 25 to 50 percent (Cooper and Monheit, 1993; Madrian, 1994; Gruber and Madrian, 1994; Anderson, 1997; Stroupe, Kinney and Knieser, 2001, Adams, 2004;

Bradley et al., 2007, 2012; Bansak and Raphael 2008; Rashad and Sarpong 2008; Tunceli et al., 2009; Boyle and Lahey, 2010). Other studies find no effects or smaller effects that in some cases attain statistical significance for specific demographic groups (HoltzEakin, 1994; Penrod, 1994, Slade, 1997; Kapur, 1998; Spaulding, 1997; Berger, Black and Scott, 2004; Dey and Flinn, 2005; Gilleskie and Lutz, 2002; Hamersma and Kim, 2009).

The existing literature generally employs one of three main identification strategies to estimate job lock. The most common approach taken in the previous literature is to use a difference-in-difference strategy that compares the probability of job mobility of otherwise similar employees who differ only in how much they value their current employer's health insurance policy. ${ }^{2}$ Examples of measures of the demand for health insurance coverage used in the literature include pregnancy of spouse, family size, family health status, and availability of alternative health insurance coverage. ${ }^{3}$ A second approach taken in the previous literature is to use changes in health insurance legislation through prices, taxes or expanded coverage as a natural experiment. For example, Gruber and Madrian (1994) use variation provided by continuation coverage mandates, Sanz Galdeano (2006) use the HIPAA reform, Bansak and Raphael (2008) use the implementation of SCHIP, Hamersma and Kim (2009) use Medicaid expansions, and

\footnotetext{
${ }^{2}$ See Madrian (1994), Kapur (1998) and Bradley et al. $(2007,2012)$ for a few examples, and Gruber and Madrian (2004) for a review of the literature.

${ }^{3}$ In their review of the literature, Gruber and Madrian (2004) discuss some concerns with this approach taken in many previous studies. A common measure of alternative health insurance coverage is spousal coverage, but this may be endogenous to the job mobility decision (Royalty and Abraham 2006). Other measures used to proxy health insurance demand are family health status and expected medical utilization. These may have relatively low power and/or be difficult to measure.
} 
Boyle and Lahey (2010) use expansions of the VA health system to test whether better alternative coverage reduces job lock. Studies using this approach also find mixed results with magnitudes that vary depending on the sub-group and the reform studied. Finally, other studies have relied on structural models of job mobility and find somewhat smaller estimates of job lock (Dey and Flinn, 2005; Gilleskie and Lutz, 2002). Health insurance and job mobility are determined simultaneously in these models.

In this paper, we take a new approach to study the question of job lock. We exploit the abrupt change in health insurance coverage occurring at age 65 due to Medicare in a regression discontinuity design (RDD). The discontinuity in coverage suggests that a comparison of job mobility for workers just below the age 65 cutoff to those just above the age 65 cutoff provides a test of the job lock hypothesis that is as close to a random experiment as possible. For identification, the RDD relies on relatively weak assumptions compared with those required for the other non-experimental approaches previously taken in the job lock literature (Lee and Lemieux 2010). Indeed, as discussed below, individual characteristics are essentially identical just before and after the threshold, mimicking the typical comparison of treatment and control characteristics in a random experiment. Although previous studies exploit the discontinuity in health insurance coverage created by Medicare (e.g. Card et al. 2008, 2009), the approach has not been previously taken to identify the effects of health insurance coverage on job mobility. ${ }^{4}$

The lack of a previous study using this identification strategy to test the job lock hypothesis is likely due to the difficulty in finding a dataset that includes a high-

\footnotetext{
${ }^{4}$ In other work, we use the approach to examine the effects of employer-based health insurance on business creation (Fairlie, Kapur and Gates 2011).
} 
frequency measure of age, a measure of job mobility, and a large enough sample size to focus around age 65. To create the high-frequency measure of age, we use a novel procedure for identifying a person's age in months from matching the four consecutive months of data for each person in the Current Population Survey (CPS). The resulting measure of age in months improves on the common use of age in quarters or years in the broader RDD literature. A monthly measure of job mobility is also needed to test the job lock hypothesis using the RDD. We take advantage of a relatively unknown survey administration variable in the CPS that measures if an individual changes jobs from the previous survey month. At the beginning of the job question section, survey-takers ask respondents whether they have the same job as last month. If respondents report no job change, survey-takers carry forward the previous month's job information. Because the CPS was not intended to be used as panel data and the question is not part of the questionnaire, the documentation of this variable is limited and the variable is not included in all releases of the data. Finally, the combination of fifteen years of matched monthly files from the CPS provides a large enough sample size to focus around the age 65 cutoff.

The RDD approach has one potential disadvantage in estimating job lock. The approach only provides a local estimate of job lock, and thus might not be generalizable to other age groups of workers. While we remain cautious about generalizing results, we provide evidence below that job mobility rates, the characteristics of job mobility, and the skill and industry composition of the workforce do not differ substantially for older workers compared to middle-age workers, and therefore there may be valuable lessons from studying this group. In any case, older workers represent a large and growing share 
of the labor force and are of interest on their own. Currently, there are 15 million male workers ages 55 and over, representing 20 percent of the total male laborforce (Toosi 2009). In the next decade, the number of older workers is projected to grow to over 20 million. Labor force participation rates among older workers are high and are projected to increase over time for the oldest groups (see Figure 1). By 2018, 63 percent of male workers ages 60-64 and 40 percent of male workers ages 65-69 are projected to be in the labor force (Toosi 2009). Furthermore, the increase in the Social Security normal retirement age to 67 for those born after 1959 may result in more near-elderly workers balancing work and health insurance in the future. Recently, debates over the federal budget deficit have turned the discussion towards also increasing the Medicare eligibility age to 67 (Kaiser Family Foundation 2011). An understanding of the factors influencing work patterns and mobility will be critical to forecasting how the near elderly workforce in the United States will evolve in the coming years and respond to these policy changes.

\section{Data}

We use data from the 1996 to 2010 monthly Current Population Survey (CPS). This survey, conducted by the U.S. Census Bureau and the Bureau of Labor Statistics, is representative of the entire U.S. population and interviews more than 130,000 individuals in approximately 60,000 households per month. Households in the CPS are interviewed each month over a consecutive four-month period in each of two rotations starting one year apart. Our study uses a novel approach of matching individual-level monthly data from the CPS to create a 4-month panel data set. By matching consecutive months of the CPS, we can identify the month in which the person's age (in years) changes, which is 
defined as the birth month. ${ }^{5}$ Since the CPS interviews households for 4 consecutive months, we can identify up to two months before the birth month, the birth month, and 2 months after the birth month. ${ }^{6}$ We cannot, however, identify the birth month of individuals whose birth month does not fall in the four month interview window. Few data sets contain a large enough sample size as well as information needed to identify exact birth month. The approach also has an advantage over many previous RDD studies that rely on age in years or quarters because we do not have to make potentially strong assumptions about the shape of the relationship between age and the outcome. The effects of age on job mobility will be small because we can narrow the focus to only a couple of months before and after the age 65 birth-month cutoff.

To measure job mobility, we take advantage of an underutilized survey administration variable in the CPS that measures if an individual changed his/her job from the previous survey month. The CPS was redesigned in January 1994, and one of the design changes aimed to avoid unnecessary duplication in the questions asked of respondents. As part of this design change some questions referred back to the answers given in the previous month. The job change variable used in this study is derived from this “dependent interviewing” approach. If a respondent is reported employed in one month and is also reported employed in the previous month's survey, the interviewer asks the respondent whether they currently work for the same employer as reported in the

\footnotetext{
${ }^{5}$ To match these data, we use the household and individual identifiers provided by the CPS. False matches are removed by comparing race, sex and age codes from the two months. All non-unique matches are also removed from the dataset. Monthly match rates are generally between 94 and 96 percent, and false positive rates are very low. Match rates are even higher among older individuals.

${ }^{6}$ As expected, we find that roughly 25 percent of the sample (3 out of 12 months in which we can observe an age change in the following month) experiences an age increase in the data. We also find very few cases in which age increases by more than one year or decreases over consecutive months. The high levels of accuracy are due to the CPS carrying forward age information for respondents based on recorded birth dates.
} 
previous month (the interviewer reads out the employer's name from the previous month to ensure accuracy). If the answer is yes, then the interviewer carries forward the industry, occupation and other job characteristics information from the previous month's survey. If the answer is no, then the respondent is asked the full series of industry, occupation, and other job questions. Using the answer to this routing question, we can identify job stayers (workers employed in two consecutive months at the same employer) and job changers (workers who changed employers between two consecutive months). The measure does not suffer from recall error associated with questions asking about retrospective information. ${ }^{7}$ This variable has been used in only a few previous studies, and none that have examined job lock. ${ }^{8}$

Panel data created by matching consecutive months of the Current Population Survey (CPS) provides a high-frequency measure of age, a measure of job mobility, and a large enough sample size to focus around age 65. Alternative datasets such as the Health and Retirement Study (HRS), American Community Survey (ACS), the Panel Study of Income Dynamics (PSID), and the Survey of Income and Program Participation (SIPP) lack one or more of these criteria. The HRS has information on age in months, but the survey is only conducted biennially. Information on job changes is collected retrospectively for the two-year period, and as a result, is much more likely to suffer from reporting error than monthly CPS data. The sample sizes of the PSID and SIPP are too

\footnotetext{
${ }^{7}$ A monthly measure of job mobility is also available in the SIPP. Monthly job mobility in the CPS is about 25\% lower than mobility in the SIPP (Nagypal, 2008). One problem with estimates of monthly job mobility rates in the SIPP, however, is they might suffer from seam bias: a disproportionate number of labor-market transitions are reported as taking place between the 4-month waves, and not over months within waves. ${ }^{8}$ Other studies that have used this variable have examined the cyclicality of mobility and job hopping in Silicon Valley (Fallick, Fleischman and Rebitzer 2004, 2006; Mazumder, 2007; Nagypal 2008).
} 
small to focus on the age 65 cutoff, and the ACS lacks information on job mobility and detailed age.

The main sample includes male workers who work 30 or more hours in a wage/salary job in the first survey month and have a wage/salary job in the second survey month in each consecutive 2-month survey pair. ${ }^{9}$ We exclude women from the analysis because of labor force participation concerns. The use of data from the 1996 to 2010 CPS implies that the women who reach age 65 in the sample were born in the 1930s. This cohort of women has a low labor force participation rate. Our analysis design requires a large number of observations, and for women there were too few observations for a fulltime worker sample around the age 65 cutoff. We also use the extensive information on demographic, job, and region characteristics available in the CPS, such as race, immigrant status, marital status, education, hours of work, industry, region and urbanicity of residence.

\section{JOB MOBILITY RATES}

Figure 2 plots job mobility rates by age for male wage/salary workers ages 25 to 70. Job mobility rates start out high for young workers, but decline rapidly with age over the next two decades. At age 25 more than 3 percent of workers change jobs each month. By age 35 the rate of job mobility drops to 2 percent and by age 45 the rate of job mobility drops to 1.5 percent. The likelihood of job mobility remains at this level for the

\footnotetext{
${ }^{9}$ This sample definition is consistent with the job lock literature. In practice, we find that the regression results are not sensitive to the choice of hours in either the first or second job. Alternative specifications that restrict to jobs with 20 or more hours worked per week or 40 or more hours worked per week show similar results.
} 
remainder of the working career. Job mobility rates for workers in their 50s and 60s are in the same range as job mobility rates for workers in their mid-40s.

Focusing on older workers, an interesting finding is that job mobility rates do not change substantially from ages 55 to 70 . There is no strong upward or downward pattern in job mobility around age 65, which makes it easier to identify changes at age 65 . The finding that job mobility rates do not fluctuate substantially in the few years around age 65 suggests that we do not need to make strong assumptions about the age/job mobility profile. Figure 2 also does not provide evidence of a large increase in job mobility rates at age 65 .

Before examining job mobility rates around the age 65 cutoff in more detail, we examine whether the characteristics of job change are different for older workers than for younger workers. Table 1 reports work characteristics of job changers by 5-year age groups. Among job movers, we find that 33.8 percent of job changers in the 60-64 age group report changing major industries, which does not differ substantially from the rate for middle-age workers. We also find that the average hours worked after the job change does not differ substantially by age group. We condition on full-time work in the initial survey month, but place no restrictions on hours worked in the subsequent survey month of the two-month panel. Older workers also have a similar rate of movement between government and non-government work as middle-age workers. Finally, the skill and industry distributions of the workforce do not change substantially over time. Older fulltime, wage/salary workers have similar educational and industry distributions as middleage workers. Overall, the characteristics of job mobility and the characteristics of the workforce do not noticeably differ for older workers than for middle-age workers 
lessening concerns that job mobility and the workforce is unique around the age 65 threshold.

\section{Age 65 Discontinuity}

To examine the question of whether health insurance discourages job mobility we exploit the discontinuity created at age 65 through the qualification for Medicare. In the month that individuals turn 65, they automatically qualify for Medicare, providing access to free health insurance coverage for hospital care and heavily subsidized coverage for other medical services. ${ }^{10}$ Card et al. $(2008,2009)$ show that health insurance coverage increases substantially at age 65. Medicare coverage is not subject to pre-existing condition exclusions or waiting periods, reducing concerns about job-lock. Attaining Medicare eligibility should immediately reduce the value an individual places on employer-sponsored health insurance. Potential job changers no longer have to be concerned about losing health insurance coverage after that date.

We can isolate the effects of the Medicare discontinuity by comparing job mobility rates just before the age 65 birth month to just after the age 65 birth month. Individuals qualify for Medicare on the first day of the month that they turn 65, and as noted above, matching consecutive months of the CPS allows us to identify the month in which they turn 65 . Since this approach is tightly focused on the months before and after the 65 birth month, it addresses concerns over the potential influence of unobservables such as health insurance preferences and individual health status on the estimates.

\footnotetext{
${ }^{10}$ Individuals automatically qualify for Medicare Part A (hospital insurance) in the month they turn age 65 if they have 40 quarters of previously covered employment or have a qualifying spouse. Medicare Part B (medical insurance) can be purchased for approximately \$100 per month.
} 
We start by graphing job mobility rates in two-month intervals around age 65 (see Figure 3). We choose a binwidth of two months to partly smooth the data for presentation. Plotting job mobility rates by one-month bins, which is the smallest possible bandwidth in the data, reveals a much noisier graph (see Appendix Figure 1). As noted above, the 4-month rotation of the CPS only allows us to identify months around the birth month, which is why the figures do not display job mobility rates for age in months in the middle of the birth year. From the plot of job mobility rates by age in two-month intervals we do not see evidence of an increase in job mobility starting at age 65. In fact, the job mobility rate appears to decrease for workers who are just under age 65 to workers who are just over age 65. Fitting simple linear regression lines to either side of the age 65 cutoff clarifies these patterns. We do not find evidence of an increase in job mobility rates after workers turn age 65 .

The estimates displayed in Figure 3 reveal another interesting pattern. Job mobility rates are relatively constant with the age of older workers. No clear upward or downward trend appears over the full age range. This finding is important because it lessens the potential for biases introduced by not accurately specifying the age-job mobility profile. The RDD results are thus likely to be insensitive to how we model the age function.

Examining trends in job mobility by age in two-month intervals does not reveal a break at age 65 . We now examine job mobility rates by age in years. Although we cannot focus in as much on the age 65 discontinuity by using age in years as the bandwidth, we can increase precision substantially. By using age in years, we are able to add back the three quarters of the original sample in which we cannot identify the exact birth month in 
the four-month CPS rotation. Figure 4 displays the results using age in years for the bins for the analysis. These are the same data that are presented in Figure 2, but here we focus on ages 60-69 and show linear regression lines on either side of the break. Similar to the results using age in two-month intervals, there is no evidence of an increase in job mobility rates at age 65 . From age 64 to age 65 there is actually a slight decline in job mobility rates, but generally there is no major change in job mobility rates over the age range. Linear regression lines on either side of the cutoff also do not reveal an increase in job mobility rates at age 65 .

\section{Regression Discontinuity Models}

We now turn to a more formal regression analysis of the age 65 discontinuity. We follow the framework and recommendations presented in Lee and Lemieux (2010) and Imbens and Lemieux (2008). We start by estimating a parametric regression for the probability of a job change. The linear model used as a starting point can be expressed as:

(4.1) $\mathrm{Y}_{\mathrm{i}}=\alpha+\beta\left(\mathrm{A}_{\mathrm{i}}-\mathrm{c}\right)+\tau \mathrm{W}_{\mathrm{i}}+\gamma\left(\mathrm{A}_{\mathrm{i}}-\mathrm{c}\right) \mathrm{W}_{\mathrm{i}}+\varphi^{\prime} \mathrm{Z}_{\mathrm{i}}+\varepsilon_{\mathrm{i}}$, where $\mathrm{c}-\mathrm{h} \leq \mathrm{A}_{\mathrm{i}} \leq \mathrm{c}+\mathrm{h}$

where $Y_{i}$ is an indicator for job change, $h$ is the bandwidth, $A_{i}$ is the individual's age in months, $\mathrm{c}$ is the cutoff (i.e. age 65 ), $\mathrm{W}_{\mathrm{i}}=1$ if the individual is age 65 or over, $\mathrm{Z}_{\mathrm{i}}$ is a vector of additional covariates, and $\varepsilon_{\mathrm{i}}$ is the error term. The specification allows for a different slope of the age/job mobility function on either side of the age 65 cutoff. The parameter 
of interest is $\tau$, which captures the change in the probability of job mobility at the age 65 threshold or the estimate of job lock.

Equation (4.1) is similar to a non-parametric, local linear regression, however, one possible concern is that the conditions for non-parametric methods are not technically satisfied in the discrete case (Lee and Card 2008). Our measure of the "forcing” or "running" variable, age in months is discrete, but as Lee and Lemieux (2010) note as long as the discrete variable is not too coarsely distributed the estimation strategy is similar. Thus, the main limitation created by our measure is that we cannot estimate local linear regressions with very small bandwidths. Choosing a bandwidth of two months, for example, would only provide two possible values for variation in the forcing variable on either side of the cutoff. Choosing a bandwidth of one month provides only one possible value on either side of the cutoff, and thus results in a simple comparison of means. Overall, however, the reduction in potential bias associated with using very narrow bandwidths is likely to be small because of the relative constancy of job mobility rates with age as displayed above. To create a large bias job mobility rates would have to change substantially over only a few months, which they do not appear to do. Additionally, information on exact birth dates could theoretically allow for smaller bandwidths, but these bandwidths (less than one month) are likely to produce very imprecise and highly variable estimates of job lock.

There are several features of the model that are advantageous in this setting. First, the forcing or running variable in the RDD, age, is immutable. Age cannot be altered to affect Medicare eligibility avoiding a potential problem with RDDs when the forcing variable can be manipulated by individuals or other participants to affect placement 
around the threshold. Second, many previous studies using age as the forcing variable rely on age in quarters. The use of age in months substantially decreases the binwidth and thus the internal validity of the approach around the threshold. Third, the CPS allows us to control for a rich set of variables that are not typically available in administrative datasets. An examination of the sensitivity of job lock estimates after the inclusion of these controls and estimates of equation (4.1) using these variables as dependent variables provides further evidence on the internal validity of the RDD in this setting. Estimates of equation (4.1) are reported in the first column of Table 2 for age ranges from 14 months to 62 months around the age 65 cutoff. The reported bandwidths or age ranges correspond to the clusters of age in months identifiable in the matched CPS. Examining observations on the left side of the age 65 cutoff for example, the smallest bandwidth reported (14 months) includes the two identifiable months just prior to age 65 and the five identifiable months clustered around age 64 (see Appendix Figure 1). Bandwidths are then increased by one-year increments to capture the next cluster of possible age in month values. For all bandwidth choices, we do not find evidence of an increase in job mobility rates from just under the cutoff to just over the cutoff. In fact, none of the point estimates using the different bandwidths are positive. Additionally, the coefficient estimates using the various bandwidths are similar to the simple mean change in job mobility rates from the month before turning age 65 to the month after turning age $65(-0.0013)$ and the change in job mobility rates from the two-month average before turning age 65 to the two-month average after turning age 65 (-0.0107).

To identify the optimal bandwidth we use the "leave one out" cross-validation procedure proposed by Ludwig and Miller (2007) and Imbens and Lemieux (2008). 
Specifically, we estimate linear regressions for each bandwidth leaving one observation out. For that observation, we then calculate the difference between actual job mobility and predicted job mobility. Using all observations in each bin, we calculate the mean square of these differences. We find that a bandwidth of 14 months minimizes the mean square of the differences, but the values are fairly similar. ${ }^{11}$ Instead of choosing a marginally preferred bandwidth we continue to present several bandwidths.

We also estimate regressions using higher-order polynomials (i.e. quadratic, cubic and quartic specifications) for the job mobility - age relationship. The quadratic specification, for example, is expressed as:

(4.2) $Y_{i}=\alpha+\beta_{1}\left(A_{i}-c\right)+\beta_{2}\left(A_{i}-c\right)^{2}+\tau W_{i}+\gamma_{1}\left(A_{i}-c\right) W_{i}+\gamma_{2}\left(A_{i}-c\right)^{2} W_{i}+\varphi^{\prime} Z_{i}+\varepsilon_{i}$, where $\mathrm{c}-\mathrm{h} \leq \mathrm{A}_{\mathrm{i}} \leq \mathrm{c}+\mathrm{h}$

The inclusion of a higher-order polynomial allows for a more flexible relationship between job mobility and age. Column 2 of Table 2 reports estimates of equation 4.2. We do not report specifications in which the order of the polynomial is smaller or the same size as the number of clusters of identifiable months otherwise the polynomial would effectively over-fit the data. An example of this problem would be estimating a quadratic specification in which we only have two clusters of identifiable months on either side of the cutoff. Estimates from the quadratic specification do not change our conclusion none of the point estimates are positive. We do not find evidence that the probability of job mobility increases at age 65 .

\footnotetext{
${ }^{11}$ We find mean square errors of $0.0138,0.0145,0.0142,0.0151$, and 0.0147 for bandwidths of 14 months, 26 months, 38 months, 50 months, and 62 months, respectively.
} 
Table 2 also reports estimates for higher-order polynomials for the age-job mobility function. The estimates for the cubic and quartic specifications do not differ substantially from the quadratic estimates. Across all bandwidths, we do not find evidence that the probability of job mobility increases at age 65 .

Specification tests along the lines suggested by Lee and Lemieux (2010) do not provide clear evidence favoring the use of higher-order polynomials over the linear specification. First, we add dummy variables for each possible age in month bin and jointly test their statistical significance. If the age bin dummies are jointly significant for a specific polynomial order then a higher-order polynomial might be needed to better fit the data. For 14-month and 26-month bandwidths, the age bin dummies are not statistically significant for the linear or higher-order specifications. For the longer bandwidths, the age bin dummies are generally significant for all polynomial orders. There is also no clear reduction in the significance level for the test when increasing the order of the polynomial. The only exception is for the 38-month bandwidth regression where moving from the quadratic specification to the cubic specification increases the pvalue from 0.022 to 0.051 favoring the cubic specification. For the second test, we conduct an Akaike test of significance that induces a penalty for adding additional variables. The AIC values are very similar across the different polynomial orders and do not provide clear evidence favoring higher-order polynomials.

We do not find that the higher-order polynomials improve the explanatory power of the regressions over the linear specifications. The discontinuity estimates are also not sensitive to the choice of polynomial order. This lack of sensitivity is perhaps not surprising given that the simple plots of job mobility rates by age did not reveal a strong 
downward or upward pattern with age. We continue by discussing results primarily from linear specifications, but report estimates for higher-order polynomials and note any major differences.

The CPS allows for a rich set of controls to be included in the regressions. Table 3 reports the same set of specifications as reported in Table 2 after controlling for individual and job characteristics. We include controls for race, nativity, married, education, region, urbanicity, industry, and year fixed effects. The inclusion of these controls has little effect on the estimates. The lack of sensitivity of the estimates to the inclusion of covariates provides additional evidence on the validity of the regression discontinuity design. The covariates appear to be unrelated to whether a person's age is just under or just over the cutoff. ${ }^{12}$

Using these estimates we examine whether we can rule out large positive effects on job mobility. Figure 5 displays regression discontinuity estimates for different bandwidths and their 95 percent confidence intervals from the linear specification. All of the point estimates are negative. For the 26-month bandwidth, we can rule out a positive job mobility effect. For three additional bandwidths, we can rule out large positive job mobility effects. These estimates rule out effects of 0.002 to 0.003 , which represent 12 to 19 percent of the job mobility rate of 0.017 at age 64 . Thus, the upper bound of the 95 percent confidence intervals rule out the large effect sizes in the range of 25-50 percent found in the review of the previous literature by Gruber and Madrian (2004). The only linear specification in which the confidence interval cannot rule out these effect sizes is

\footnotetext{
${ }^{12}$ A comparison of means of the independent variables for observations just under age 65 and just over age 65 reveals that they are very similar.
} 
the 62-month bandwidth, but the upper bound is only 0.0047 or 27 percent and this is the longest bandwidth that we estimate.

Examining the 95 percent confidence intervals resulting from the higher-order polynomial specifications, we also find that we can rule out the large effects often found in the previous literature. In most cases, we can also rule out positive or small positive effects on job mobility. Using the quadratic specification, for example, we can rule out positive effects for two bandwidths and positive effects of 3 to 13 percent for the other two bandwidths. These results further support the conclusion that our estimates can rule out large job mobility effects. ${ }^{13}$

\section{AGE IN YEARS}

We estimate regressions using age in years as the forcing variable. As noted above, a major advantage of this approach is that we can use the full sample, which is four times larger than the sample in which we can identify age in months from the rotation pattern in the CPS. Table 4 reports estimates. Similar to the estimates using age in months as the forcing variable, we do not find evidence of a positive effect of turning age 65 on job mobility. All of the point estimates from the various bandwidths and polynomial orders are not positive and are very small. The coefficient estimates are also relatively similar across bandwidths and polynomial orders. We do not find evidence of a preference for using a higher-order polynomial to estimate the discontinuity.

\footnotetext{
${ }^{13}$ By constraining the slopes on either side of the age 65 threshold to be the same we can further improve the precision of our estimates. The constancy of job mobility rates by age suggests that constraining the slopes to be equal does not seem like an overly restrictive assumption. In many cases, 95 percent confidence intervals can rule out even larger effects.
} 
Controlling for demographic and work characteristics has little effect on the estimates. Table 5 reports estimates of the regressions including controls. The coefficient estimates are very similar to those reported in Table 4 without the controls. Again, the covariates appear to be unrelated to age around the discontinuity. We find no evidence of job lock.

Using the age in years specification we can rule out large, positive effects of job lock for older workers. Figure 6 displays estimates and their 95 percent confidence intervals from the linear specifications by bandwidth. All of the point estimates are negative and in this case their standard errors are precise enough that we can rule out the possibility of large positive effects. For two specifications the upper bound of the 95 percent confidence interval rules out effects larger than 10 percent of the mean job mobility rate. In two additional specifications, we can rule out estimates that are more than 15 percent of the job mobility rate. The largest upper bound can rule out positive effects that are more than 20 percent of the job mobility rate. Similar to the estimates measuring age in months we can rule out large positive job lock effects.

\section{SPECIFICATION CHECKS}

\section{Extending the Age Range}

Because of the lack of substantial trends in job mobility over age, we extend the age range used in the sample. Table 6 reports estimates for bandwidths of 72 months to 122 months (roughly 6-10 years on either side of the cutoff). For the linear specification the point estimate for job lock remains negative and small using the 72 month to 98 
month bandwidths. The point estimates become positive, but very small for the 110 month and 122 month bandwidths. For the quadratic and higher-order polynomials the estimates do not differ substantially from the estimates using the smaller bandwidths. In all cases, the point estimates are negative and we can rule out large positive effects. The longer bandwidths provide more precision and allow us to rule out even smaller positive effects in many cases. Most of the estimates for the cubic and quartic specifications allow us to rule out any positive effects. For instance, for the quartic specification with bandwidths of 98 - 122 months, the $95 \%$ confidence interval allows us to rule out the existence of any job lock.

Table 7 reports estimates for bandwidths of 6-10 years using age in years as the forcing variable. Again, the estimates do not differ substantially from the shorter bandwidths. All of the estimates allow us to rule out large, positive job lock effects.

\section{Age Masking in the CPS}

Starting in August 2002, the Census Bureau "masked" the age variable for some respondents ages 65 and over in the CPS to protect confidentiality (U.S. Census Bureau 2010). Although it does not appear to have substantially affected male sample counts by age (U.S. Census Bureau 2010), we investigate whether our estimates are sensitive to the age masking because of the focus on the age 65 cutoff. ${ }^{14}$ The random age masking only affects respondents who are age 65 and over in the first interview month in the CPS, and only assigns new values of 65 and over. No one aged 64 and below is affected by the

\footnotetext{
${ }^{14}$ The weighted population counts for ages 65 for the unperturbed and perturbed data are only 6 percent different. The differences are even smaller for ages 66-69 averaging only 1 percent (U.S. Census Bureau 2010). The age perturbation, however, appears to have had a larger effect on estimates of sex ratios for the age 65 and over population.
} 
masking, and the sequence of age values in the subsequent survey months cannot be altered from its expected path (even after turning age 65). ${ }^{15}$ Because of these procedures, the age masking does not affect age immediately around the age 65 threshold for our sample. Thus, using our measure of age in months individuals ages 64 and 65 cannot be affected by the masking. For at least some respondents ages 65.8, 65.9, and 66-69, however, it adds noise to their recorded ages, which might have an effect on the estimates.

To check the sensitivity of results, we first exclude all observations in which there might be an age perturbation. We do not know which observations experienced the age masking because of the confidentiality requirements so we exclude all observations that might have been affected as a conservative approach. This includes observations for ages 65.8 and over starting in the August 2002 CPS. Individuals turning age 65 in the first sample rotation, are age 65 in the second sample rotation, and in some cases turning 66 in the second rotation are not excluded, however, because these individuals were age 64 in the first survey month in the CPS, and thus were not eligible for potential age masking. Appendix Figure 2 displays estimates from this modified sample. Excluding all observations with the possibility of having a masked age value does not the change the result. The figure shows a similar pattern in which there is no evidence of positive job lock. When we use age in years we also find no evidence of a positive effect when we exclude all observations that might have experienced an age perturbation in the CPS. The similarity is not surprising as the age masking does not affect ages through age 65 and simply adds some noise to the age measure for those 65 and over. The lack of a strong

\footnotetext{
${ }^{15}$ The age perturbation only alters the recorded birth year, and as noted above, the birth date is used to determine the age sequence across months in the CPS not month-to-month self-reported ages.
} 
age profile also makes the effect of potential age masking on observations above age 65

less of a concern because we are primarily comparing average levels of job mobility prior to age 65 and post age 65.

\section{Density around the Cutoff}

An important assumption for the validity of the RDD is that individuals do not have precise control over the forcing variable. In our setting this assumption is valid because individuals have no control over their age. But, turning age 65 might be associated with other changes affecting the probability of being in the sample. We investigate this issue in two ways. First, we follow the approach suggested by McCrary (2008) of examining whether there is a discontinuity in the sample frequency counts around age 65. Second, we examine whether there is a discontinuity in the probability of being in the analysis sample, which differs from examining frequency counts in that we are conditioning on being in the CPS data.

Figure 7 displays weighted frequency counts in two-month intervals for the age 60 to 70 range. A fitted linear regression line allowing different slopes on either side of the cutoff is also displayed. The estimates do not indicate a break at age 65 in sample frequencies relative to what is predicted. The sample size is declining with age, partly because older workers are leaving the labor force or reducing hours worked, but the change in the slope of the linear prediction at age 65 is not statistically significant.

Conditioning on being in the CPS data does not change the conclusion. Figure 8 displays the average probability of being in the analysis sample for two-month windows and a fitted linear specification. Similar to the weighted frequencies, the in-sample rate is 
declining with age, but the estimates do not reveal a change at the age 65 cutoff that is out of line with what is predicted. The regression estimates of the predicted change at age 65 are small and statistically insignificant for the linear and quadratic specifications.

The analysis for both ways of measuring the sample density does not reveal a break at age 65 . This is not entirely surprising, as individuals cannot control their age. They can control whether they are in the labor force by retiring, however, which affects the probability of being in the sample. We investigate this question more specifically in the next section.

\section{CHANGES IN COVARIATES}

Next, we examine if any of the covariates change at the age 65 cutoff. Given that the forcing variable is age this seems unlikely, but nonetheless we explore this possibility. If discontinuities exist in any of the control variables then it could signify that other policies or economic factors might be changing at the age 65 cutoff. We explore for potential discontinuities in several of the demographic and work variables. As an example, Figure 9 displays estimates of the minority share of the sample by age in 2 months around the age 65 cutoff. As expected there is no discontinuous break for this measure. Figure 10 similarly indicates no discontinuous break at age 65 for the percent of the workforce with a college education. The finding is consistent across the other controls and is consistent with Card et al. (2008, 2009) who do not find evidence of changes in marriage, family income and household moves at age 65.

The lack of finding breaks in any of the demographic and work characteristic controls in the CPS provides further evidence on the internal validity of the RDD. The 
lack of a significant change in the covariates around the threshold is similar to the finding of no difference in mean values in a randomized control experiment (Lee and Lemieux 2010).

\section{Health Insurance Coverage, Retirement, Social Security and Other Potentially Confounding Factors}

EMPLOYER PROVIDER HEALTH INSURANCE COVERAGE

The basic monthly files of the CPS do not include information on health insurance coverage. We thus cannot limit our sample to only those male workers covered by employer provided health insurance in the initial survey month. To explore the implications of this potential problem we use the March CPS files to estimate the percentage of male full-time, wage/salary workers age 64 who are covered by employer provided health insurance. We find that a large percentage of these workers (75 percent) are covered suggesting that this does not pose a serious problem for our estimates. Although we cannot limit the sample to include only individuals at risk of losing employer provided health insurance we can approximate the effect by scaling up the previous "reduced-form" coefficients by dividing them by $0.75 .{ }^{16}$ Using this adjustment, we can continue to rule out the large positive effects found in previous studies. Using age in months as the forcing variable, the upper bounds of the adjusted estimates are generally below 15 percent. Using age in years as the forcing variable we can rule out similarly large job lock effects. The adjustment has little effect on the results because a

\footnotetext{
${ }^{16}$ Another potential problem would arise if not everyone qualified for Medicare when they turned age 65 . Medicare coverage is nearly universal, however, for this group of male, full-time workers because eligibility is based on having (or their spouse having) a minimum of 10 years of Medicare-eligible work history. For all individuals ages 65 and over, 94 percent are covered by Medicare suggesting that our group of male full-time workers have even higher eligibility rates (U.S. Census, 2010).
} 
very high share of male wage and salary workers with 30 or more hours worked per week are covered by employed provided health insurance.

We investigate this issue further by splitting the sample into two groups delineated by their predicted rates of having employer provided health insurance just prior to turning 65 . We create a sample of male full-time workers with high rates of predicted employer provided health insurance and a sample with low rates of predicted employer provided health insurance. We estimate the coefficients used for calculating predicted employer provided health insurance coverage rates using a sample from the March CPS. The regression includes controls for age, race, education, marital status, region, industry, and year dummies. We predict employer provided health insurance probabilities from the basic monthly sample at age 64 . Predicted values above the median are placed in the high employer provided health insurance coverage rate group and those below the median are placed in the low coverage rate group. Estimates are displayed in Figures 11A and 11B. We do not find evidence of an increase in job mobility at the age 65 threshold for either sample.

Another concern is that some government employees may have access to government provided retiree health insurance even if they switch to another job. Portability of health insurance could lessen the effects of job lock for this group of workers which might be reducing our estimates of job lock. To address this concern, we estimate regressions in which we exclude the 18 percent of all workers that work in the government sector from the sample. Public sector retiree health insurance plans differ widely in their eligibility requirements and premium contributions by state or local area (Clark 2008). We have no information on eligibility for these plans in the data so we take 
the conservative approach of excluding all government workers. Figure 12 displays rates of job mobility for non-government workers and regression estimates. Excluding government workers does not result in a positive estimate of job lock, and the estimates are roughly similar to those estimated with the full sample.

\section{RETIREMENT AND HOURS WORKED}

One concern is that the age of 65 may be associated with other labor force transitions. Other than changing jobs, individuals may retire or reduce their hours worked per week. ${ }^{17}$ Our analysis design is suitable for examining these transitions as well, and allows us to examine whether there are changes around the age 65 birth-month. First, we examine whether the likelihood of retiring changes at the age 65 cutoff. Figure 13 displays retirement hazard rates in two-month intervals around age 65. The dependent variable is whether the wage/salary worker with $30+$ hours in the initial survey month retires by the subsequent survey month. There does not appear to be an increase in retirement at the age 65 cutoff although there is some noise in the displayed retirement hazard rates. Table 8 reports regression estimates for the retirement probability using different bandwidths and polynomial orders. The results paint a consistent story - there is no evidence of a statistically significant positive effect on retirement. ${ }^{18}$ All of the coefficient estimates are small and statistically insignificant. Although qualifying for Medicare at age 65 might reduce the influence of employer based health insurance on retiring it may represent a small effect relative to loss of income.

\footnotetext{
${ }^{17}$ Previous research provides evidence that health insurance costs reduce retirement rates (see Johnson et al., 2003 for example).

${ }^{18}$ This finding also lessens concerns that Medicare-induced job mobility occurs through job to retirement to unretirement transitions that we would miss with the monthly job change measure available in the CPS. See Maestas (2010) for evidence of unretirement patterns among older workers.
} 
We also examine whether hours worked changes at the age 65 threshold. Mean hours worked per week in the subsequent survey month is high for this group because we are conditioning on full-time work in the initial survey month. The predicted lines suggest only a slight drop in hours worked, but the difference of 0.25 hours is not statistically significant. There is essentially no decline in actual average hours worked just below the age 65 cutoff (42.0 hours) to just above the age 65 cutoff (41.9 hours). In estimating the full set of regression specifications with various bandwidths and polynomial orders, reported in Table 9, we find a range of values, but the coefficients are small and are almost all statistically insignificant. Overall, we do not find evidence indicating that there is a large change in hours worked when workers turn age 65.

Changes in the composition of the labor force or other labor market changes do not appear to be confounding our estimates of the change in job mobility at 65 . This finding is consistent with estimates reported in Card et al. (2008, 2009). In previous research, we find that self-employment rates increase at age 65; however, our current study analyzes transitions from wage and salary work to wage and salary work and therefore excludes transitions to self-employment (Fairlie, Kapur and Gates, 2011). Our analysis excludes a very small proportion of employment transitions, since only 0.04 percent of those around age 65 transition into self-employment.

\section{OTHER POLICY CHANGES AT AGE 65}

Another issue with the regression discontinuity estimates is that there might exist policy-related confounding factors that lead to shifts in employment behavior at age 65 such as eligibility for Social Security or pensions. However, Social Security eligibility 
does not appear to confound our analysis of job mobility precisely at age 65 for two main reasons. First, the earliest age of eligibility for Social Security benefits is 62; benefits received by individuals at that point are reduced (in an actuarial neutral way) relative to what would be received if one were to retire at the full retirement age. Administrative data on Social Security benefits reveal that individuals are far more likely to begin claiming benefits at age 62 than at age 65 (Munnell and Sass 2007). In 2004, 56 percent of eligible men elected to receive Social Security benefits starting at age 62 compared with 23 percent when they turned 65.

Second, while the full retirement age for full Social Security benefits was 65 for individuals born in 1937 or earlier (i.e., those reaching eligibility before 2003), Social Security reform enacted into law in 1983 increased the full retirement age by two-month increments per year of birth beginning with the 1938 birth cohort until it reached 66 for those born in $1943 .{ }^{19}$ The cohorts affected by the reform reached their full retirement age in 2003-2010, which is covered in our sample period. ${ }^{20}$ For these cohorts, the propensity to claim Social Security exactly at age 65 has fallen dramatically because of the change in the full retirement age. For example, for the 1939 birth cohort with the full retirement age of 65 years and 4 months, almost 50 percent claimed Social Security at age 62, and about 16 percent claimed at 65 years and 4 months; however, there was no spike in the claiming rate at age 65 with only about $2-3$ percent claiming in that month. Thus, the

\footnotetext{
${ }^{19}$ For cohorts born between 1943 and 1954 the full retirement age remains at 66. For subsequent cohorts, the full retirement age will increase in 2 month increments until it reaches 67. However, these younger cohorts do not reach retirement age in our sample period (http://www.ssa.gov/retire2/retirechart.htm). ${ }^{20}$ In 2000, Social Security eliminated the earnings test for claiming between ages 65 and 69. Empirically, the effect of the increase in the full retirement age dominates the elimination of the earnings test for cohorts that retire after 2003, and therefore, there is no increase in the Social Security claiming exactly at age 65 (Song and Manchester, 2007).
} 
increase in the full retirement age further reduces the potential effect of the age 65 threshold on Social Security claiming behavior (Song and Manchester, 2007). ${ }^{21}$

Similarly, age 65 does not appear to be a primary focal point for the accrual or availability of pension wealth. Under defined contribution retirement plans, pension wealth accrual does not vary substantially by age; pension wealth continues to increase as long as a person works. The critical age for individuals covered under defined contribution plans is 59.5 because at that age individuals can begin withdrawing from a 401(k) without penalty (Friedberg and Webb, 2003). Under defined benefit plans, pension wealth accrual peaks at the age of early retirement eligibility, which is well before age 65. Pension wealth may continue to increase up to age 65 (Friedberg and Webb, 2003; Poterba, Venti and Weiss, 2001). In both the case of Social Security and pensions the evidence provided in previous studies does not indicate a major change in take-up at age 65.

\section{CHANGES AT OTHER AGES}

We investigate whether there are any breaks in job mobility in other birth months. Eligibility for other social programs, such as Social Security, falls on birthdays or birth months, and there could be an independent “celebratory” birthday effect. Table 10 reports estimates for job mobility regressions using all ages as cutoffs from age 60 to 70 . Estimates from a linear specification with a bandwidth of 62 months are reported, but the findings are similar using a quadratic specification. The estimates do not indicate a

\footnotetext{
${ }^{21}$ We find no evidence of job lock effects when we restrict the sample to cohorts born in 1938 or later, and thus do not receive full Social Security benefits at age 65.
} 
statistically significant break at any age. Thus, we do not find evidence that job mobility increases discontinuously in any of the birth months when individuals turn ages 60 to 70 .

\section{Conclusions}

A major concern with the U.S. focus on employer provided health insurance is that it might restrict job mobility. The potential loss or disruption in health insurance coverage due to pre-existing condition limitations, waiting periods for coverage, changes in health plans and providers, and risk of high health costs while uninsured may dissuade many employees from leaving their job to seek a new one when it would otherwise be optimal. A relatively large literature has examined job lock and found somewhat mixed results - some studies have estimated that job lock may be responsible for a $25-50 \%$ reduction in job mobility whereas others have found small or no effects. We take a new approach in the job lock literature by examining the discontinuity created at age 65 through the qualification for Medicare. By using a novel procedure of identifying age in months from matched monthly CPS data and a relatively unknown administrative variable on job mobility, we compare the probability of changing jobs among male workers in the months just before turning age 65 to the probability of changing jobs in the months just after turning age 65. We find no evidence of an increase in job mobility after workers become eligible for Medicare. None of the RDD estimates are positive. The upper bound of 95 percent confidence intervals for these estimates can also rule out the existence of any job lock in some cases, and in most cases can rule out the large levels of job lock found in many previous studies in the literature. These results are robust to 
different bandwidths, polynomial orders for the age function, annual vs. monthly age measurement, and inclusion of controls for detailed individual and worker characteristics.

In examining the possibility that other factors confound the results for job lock, we do not find any evidence that retirement, work hours, sample densities, demographics, or work characteristics change at age 65 . This is consistent with evidence provided in previous studies using the Medicare discontinuity to examine the effects of health insurance coverage on health outcomes (e.g. Card et al. 2008, 2009). There also is no evidence that other policies potentially affecting job mobility occur at age 65 . Age 65 is considered the full retirement age for Social Security for cohorts in 1937 or earlier, but benefit eligibility starts at age 62 and benefit levels increase smoothly up to age 65 . Furthermore, for cohorts born after 1937, the full retirement age for Social Security benefits is after the $65^{\text {th }}$ birthday, reducing the probability of claiming Social Security at age 65 .

The finding of no job lock for workers at age 65 provides suggestive evidence that employer provided health insurance is unlikely to limit job mobility for other middleaged and older workers. Our descriptive statistics suggest that older workers do not look that different than middle-aged workers. A large share remains in the labor force and job mobility rates are similar to other non-young workers. The characteristics of job changes for this group and overall labor force characteristics do not differ substantially from middle-aged workers. Additionally, we might expect a priori that older workers are more likely to be affected by job lock because of higher demand for health care. Average annual total health care expenditures for people ages 45 to 64 are $\$ 5,843$ compared with $\$ 2,974$ for people ages 18 to 44 , and 89 percent of people ages 45 to 64 incur some 
expense. Over three-quarters of 45-64 year olds have one or more chronic condition (AHRQ 2008). Even if older workers have a higher demand for health care, it is important to remain cautious about extrapolating our results to younger workers who differ in their job attachment and mobility.

The findings are also important for understanding the labor market decisions of a large and growing share of the labor force -- the near-elderly. Workers ages 55 and over are projected to total more than 20 million by 2018. Increases in the Social Security normal retirement age to 67 and recently proposed increases in the Medicare eligibility age may result in an increased number of older workers balancing work and health insurance in the future. 


\section{References}

Adams, Scott (2004). "Employer-Provided Health Insurance and Job Change” Contemporary Economic Policy, Vol 22, No 3, July 2004, pp. 357-369.

Agency for Healthcare Research and Quality (AHRQ). 2008 Medical Expenditure Panel Survey: MEPSNet Query Tables. Rockville, Md.: AHRQ. http://www.meps.ahrq.gov/mepsweb/data_stats/MEPSnetHC.jsp

Anderson, Patricia M. (1997). "The Effect of Employer-Provided Health Insurance on Job Mobility: Job-Lock or Job-Push?” Unpublished Paper (Dartmouth College).

Bansak, Cynthia and Steven Raphael (2008). “The State Children’s Health Insurance Program and Job Mobility: Identifying Job Lock among Working Parents in Near-Poor Households. Industrial and Labor Relations Review, 61(4): 564-579.

Berger, Mark, Dan Black, Frank Scott (2004). "Is There Job Lock? Evidence from the Pre-HIPAA Era,” Southern Economic Journal, 2004, 70 (4): 953-976.

Bovbjerg, Randall, Stan Dorn, Juliana Macri and Jack Meyer (2009). “COBRA Subsidies for Laid-Off Workers: An Initial Report Card,” The Commonwealth Fund Issue Brief. December 2009.

Boyle, Melissa and Joanna Lahey (2010): "Health insurance and the Labor Supply Decisions of Older Workers: Evidence from a U.S. Department of Veterans Affairs expansion. Journal of Public Economics 94: 467-478

Bradley, Cathy, David Neumark, Zhehui Luo, and Heather Bednarek (2007). "Employment-Contingent Health Insurance, Illness, and Labor Supply of Women: Evidence from Married Women with Breast Cancer.” Health Economics 16: 719-737.

Bradley, Cathy, David Neumark, and Scott Barkowski (2012). “Does Employer Provided Health Insurance Constrain Labor Supply Adjustments to Health Shocks? New Evidence on Women Diagnosed with Breast Cancer.” NBER Working Paper 18060.

Card, David, Carlos Dobkin, and Nicole Maestas (2009). "Does Medicare Save Lives?” Quarterly Journal of Economics 124(2): 597-636.

Card, David, Carlos Dobkin, and Nicole Maestas (2008). "The Impact of Health Insurance Status on Treatment Intensity and Health Outcomes." American Economic Review 98(5): 2242-58.

Clark, Robert (2008). The Crisis in State and Local Government Retiree Health Benefit Plans: Myths and Realities. Center for State and Local Government Excellence. Issue Brief. Washington, DC. 
Cooper, Philip, Alan Monheit (1993). "Does Employment-Related Health

Insurance Inhibit Job Mobility?" Inquiry 30(4): 400-416.

Dey, Matthew and Christopher Flinn (2005). "An Equilibrium Model of Health Insurance Provision and Wage Determination," Econometrica 73(2): 571-627.

Eibner, Christine, Frederico Girosi, Carter Price and Elizabeth McGlynn (2010).

Grandfathering in the Small Group Market Under the Patient Protection and Affordable Care Act. RAND Policy Insights, RAND OP-313.

Fallick , Bruce, Charles A Fleischman, and James Rebitzer (2004). "Employer-toEmployer Flows in the U.S. Labor Market: The Complete Picture of Gross Worker Flows," Finance and Economics Discussion Series 2004-34, Board of Governors of the Federal Reserve System.

Fallick , Bruce and Charles A Fleischman and James Rebitzer (2006). "Job-Hopping in Silicon Valley: Some Evidence Concerning the Microfoundations of a High-Technology Cluster," The Review of Economics and Statistics 88(3): 472-481.

Fairlie, Robert, Kanika Kapur, Susan Gates (2011). Is Employer-Based Health Insurance a Barrier to Entrepreneurship?” Journal of Health Economics 30: 146-162.

Friedberg, Leora and Webb, Anthony (2003). "Retirement and the Evolution of Pension Structure”. NBER Working Paper No. W9999. Available at SSRN: http://ssrn.com/abstract=450900.

Fronstin, Paul (2010). "Sources of Health Insurance and Characteristics of the Uninsured: Analysis of the March 2010 Current Population Survey” EBRI Issue Brief No. 347.

Fronstin, Paul (2010). "Examination of the Short-Term Impact of the COBRA Premium Subsidy and Characteristics of the COBRA Population” EBRI Notes 31(6): 8-12.

GAO (2005). "Older Workers: Labor Can Help Employers and Employees Plan Better for the Future,” Report to Congressional Committees. GAO 06-80.

Gilleskie, Donna B, and Byron Lutz (2002). "The Impact of Employer-Provided Health Insurance on Dynamic Employment Transitions,” Journal of Human Resources, 37: 129162.

Gruber, Jonathan and Brigitte C. Madrian (1994). "Health Insurance and Job Mobility: The Effects of Public Policy on Job-Lock," Industrial and Labor Relations Review 48(1): 86-102.

Gruber, Jonathan and Brigitte C. Madrian (2004). "Health Insurance, Labor Supply and Job Mobility: A Critical Review of the Literature," in Catherine G. McLaughlin, ed., Health Policy and the Uninsured (Urban Institute Press: Washington, DC) 97-178. 
Hamersma, Sarah and Matthew Kim (2009) “The effect of parental Medicaid expansions on job mobility” Journal of Health Economics 28: 761-770

Holtz-Eakin, Douglas (1994). "Health Insurance Provision and Labor Market Efficiency in the United States and Germany,” in Rebecca. M. Blank, ed., Social Protection Versus Economic Flexibility: Is There a Tradeoff? (University of Chicago Press: Chicago) 157187.

Imbens, Guido and Thomas Lemieux (2008). "Regression discontinuity designs: A guide to practice,” Journal of Econometrics 142: 615-635.

Johnson, R., A. Davidoff,and K. Perese (2003). "Health Insurance Costs and Early Retirement Decisions," Industrial and Labor Relations Review, 56 (4): 716-729.

Kaiser Family Foundation (2011). Raising the Age of Medicare Eligibility: A Fresh Look Following Implementation of Health Reform.

Kapur, Kanika (1998). “The Impact of Health on Job Mobility: A Measure of Job Lock,” Industrial and Labor Relations Review 51(2): 282-297.

Lee, David and David Card (2008). "Regression Discontinuity Inference with Specification Error,” Journal of Econometrics 142 (2): 655-674.

Lee, David and Thomas Lemieux (2010). "Regression Discontinuity Designs in Economics," Journal of Economic Literature 48(2): 281-355.

Ludwig, Jens, and Douglass Miller. 2007. “Does Head Start Improve Children’s Life Chances? Evidence from a Regression Discontinuity Design,” Quarterly Journal of Economics, 122(1): 159-208.

Madrian, Brigitte (1994). "Employment-Based Health Insurance and Job Mobility: Is there Evidence of Job-Lock,” Quarterly Journal of Economics 109(1): 27-54

Maestas, Nicole (2010). "Back to Work: Expectations and Realizations of Work after Retirement," Journal of Human Resources, 45(3): 718-748.

Maestas, Nicole and Julie Zissimopoulos (2010). "How Longer Work Lives Ease the Crunch of Population Aging” Journal of Economic Perspectives 24(1): 139-160

Mazumder, Bhashkar (2007). New Evidence on Labor Market Dynamics over the Business Cycle. Economic Perspectives. Federal Reserve Bank of Chicago.

Munnell, Alicia H. and Steven A. Sass (2007). “The Labor Supply of Older Americans”. Center for Retirement Research at Boston College, CRR-WP 2007-12. Available on-line: 
http://crr.bc.edu/images/stories/Working_Papers/wp_2007-

12.pdf?phpMyAdmin=43ac483c4de9t51d9eb41 (as of October 24, 2008).

Nagypal, Eva. (2008). "Worker Reallocation over the Business Cycle: The Importance of Employer-to-Employer Transitions.” Department of Economics, Northwestern University.

Penrod, John R. (1994). “Empirical Essays in the Economics of Labor and Health.” Ph.D. Dissertation, Princeton University.

Poterba, James M., Venti, Steven F. and Wise, David A. (2001). "The Transition to Personal Accounts and Increasing Retirement Wealth: Macro and Micro Evidence". NBER Working Paper No. W8610. Available at SSRN: http://ssrn.com/abstract=291285.

Rashad, Inas and Eric Sarpong (2008). "Employer-Provided Health Insurance and the Incidence of Job-Lock: A Literature Review and Empirical Test” Expert Review of Pharmacoeconomics \& Outcomes Research, 8(6): 583-591, December 2008.

Royalty, Anne and Jean Abraham, 2006 Health Insurance and Labor Market Outcomes: Joint Decision-Making within Households", Journal of Public Economics, vol. 90 (89):1561-1577.

Sanz-de-Galdeano, Anna (2006) "Job-Lock and Public Policy: Clinton's Second Mandate,"Industrial \& Labor Relations Review, Vol. 59, No. 3, article 5: 430-437.

Slade, Eric P. (1997). "The Effect of the Propensity to Change Jobs on Estimates of 'JobLock', " Unpublished Paper (Johns Hopkins University).

Song, Jae and Joyce Manchester (2007). "Have People Delayed Claiming Retirement Benefits? Responses to Changes in Social Security Rules.” Social Security Bulletin Vol. 67, No. 2.

Spaulding, James Wallace (1997). “Fringe Benefits, Job Quality, and Labor Mobility: Pension and Health Insurance Effects on Job-Change Decisions.” Ph.D. Dissertation, University of Wisconsin-Madison.

Stroupe, Kevin T., Eleanor D. Kinney and Thomas J. Kniesner (2001). "Chronic Illness and Health Insurance-Related Job Lock," Journal of Policy Analysis and Management 20(3): 525-544.

Toossi, Mitra (2009). "Labor Force Projections to 2018: Older Workers Staying More Active.” Monthly Labor Review, November 2009.

Tunceli, Kaan, Pamela Farley Short, John Moran, and Ozgur Tunceli (2009): "Cancer Survivorship, Health Insurance, Employment Transitions among Older Workers.” Inquiry 46: $17-32$ 
U.S. Census Bureau (2007). Current Population Survey. http://www.census.gov/cps/

Zissimopoulos, Julie, and Lynn A. Karoly. 2007.“Transitions to Self-Employment at Older Ages: The Role of Wealth, Health, Health Insurance and Other Factors.” Labour Economics, 14(2): 269-95.

Zissimopoulos, Julie and Lynn Karoly (2008). "Labor Force Dynamics at Older Ages: Movements in Self-employment for Workers and Nonworkers" in Research on Aging 31(8). Available electronically at:

http://roa.sagepub.com/cgi/rapidpdf/0164027508324642v1 (October, 2008). 
Appendix Figure 1: Job Mobility Rates by Age in 1-Month Intervals

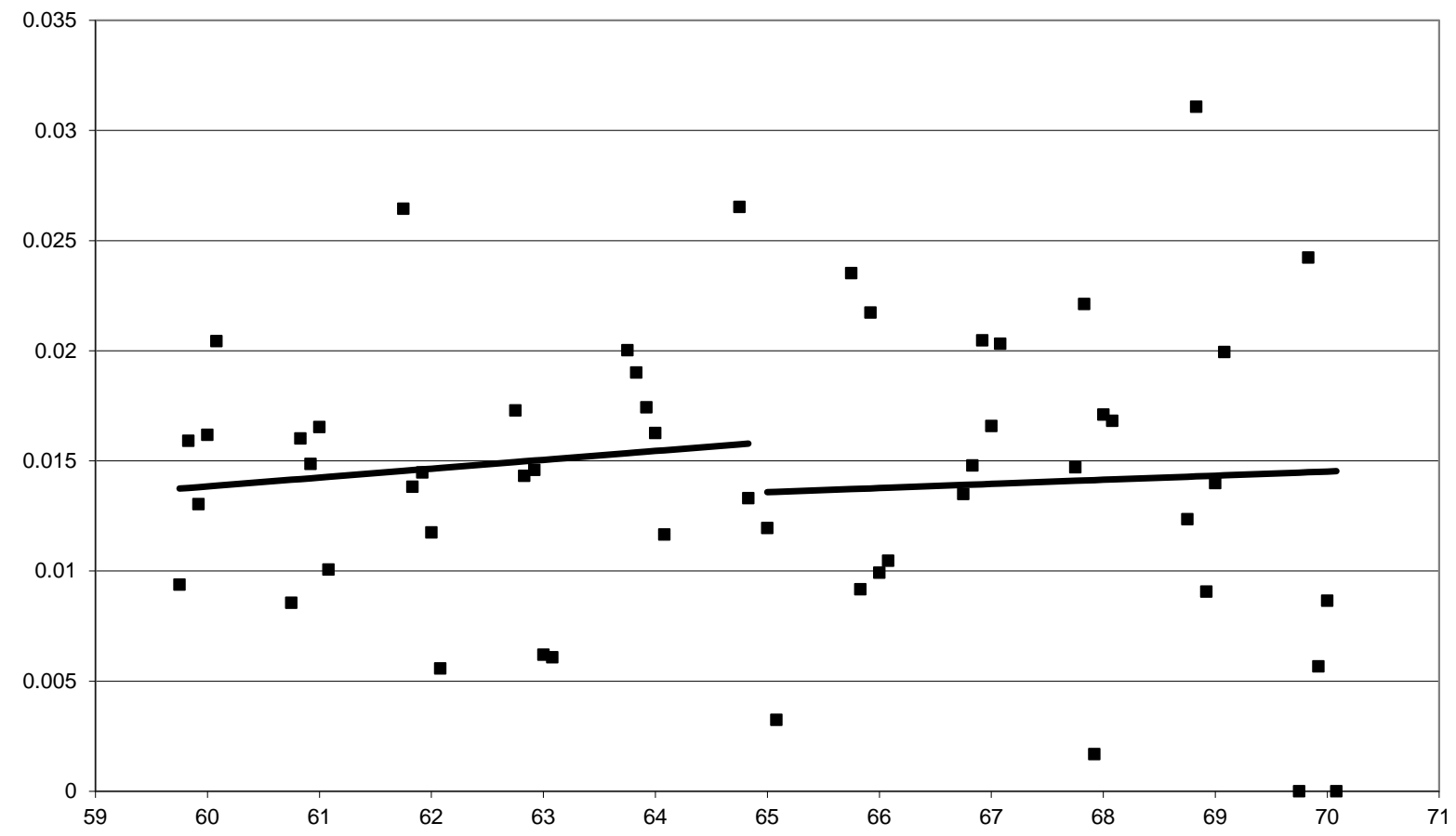


Appendix Figure 2: Job Mobility Rates by Age in 2-Month Intervals

Excludes Any Potentially Masked Age Values

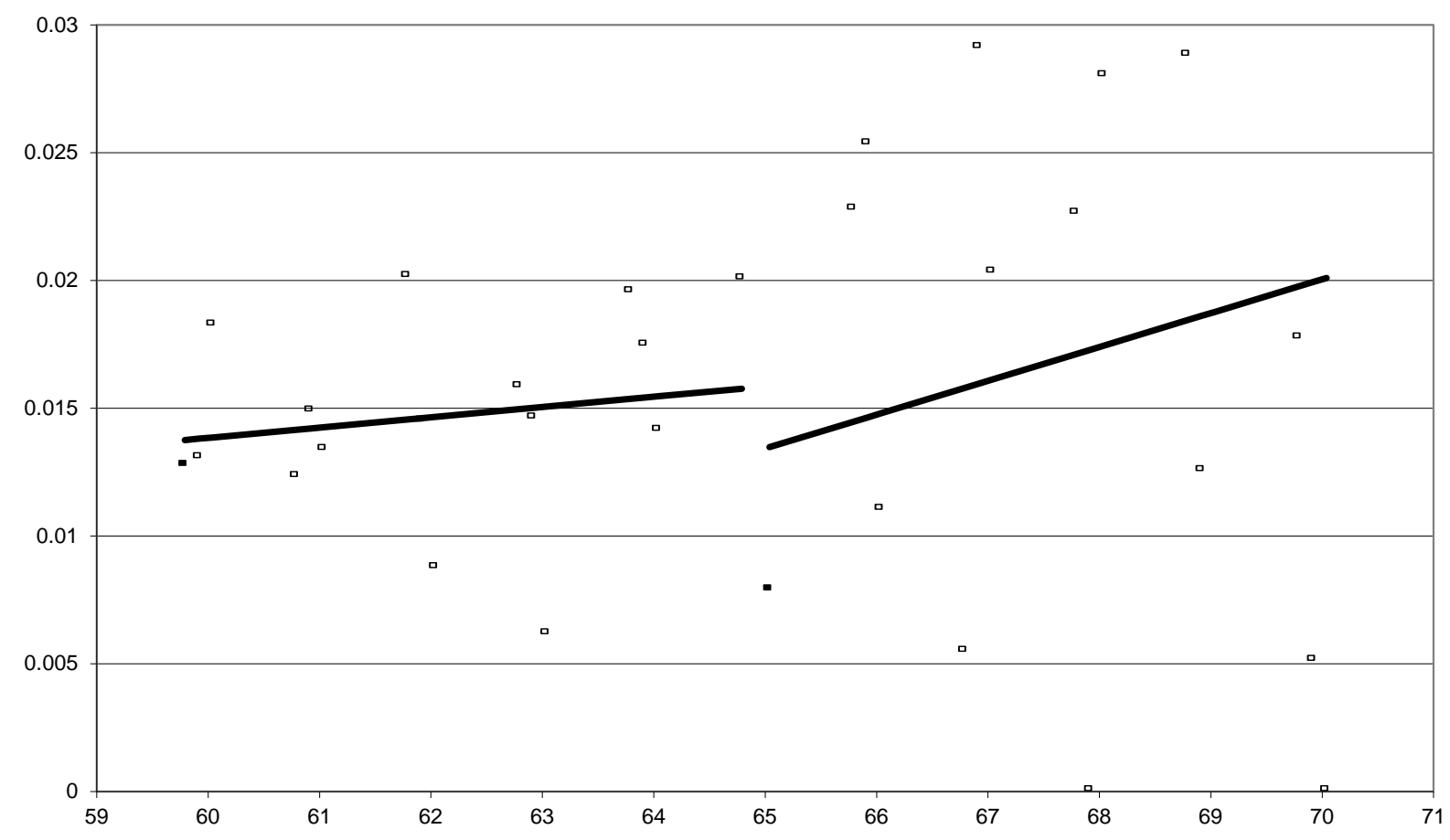




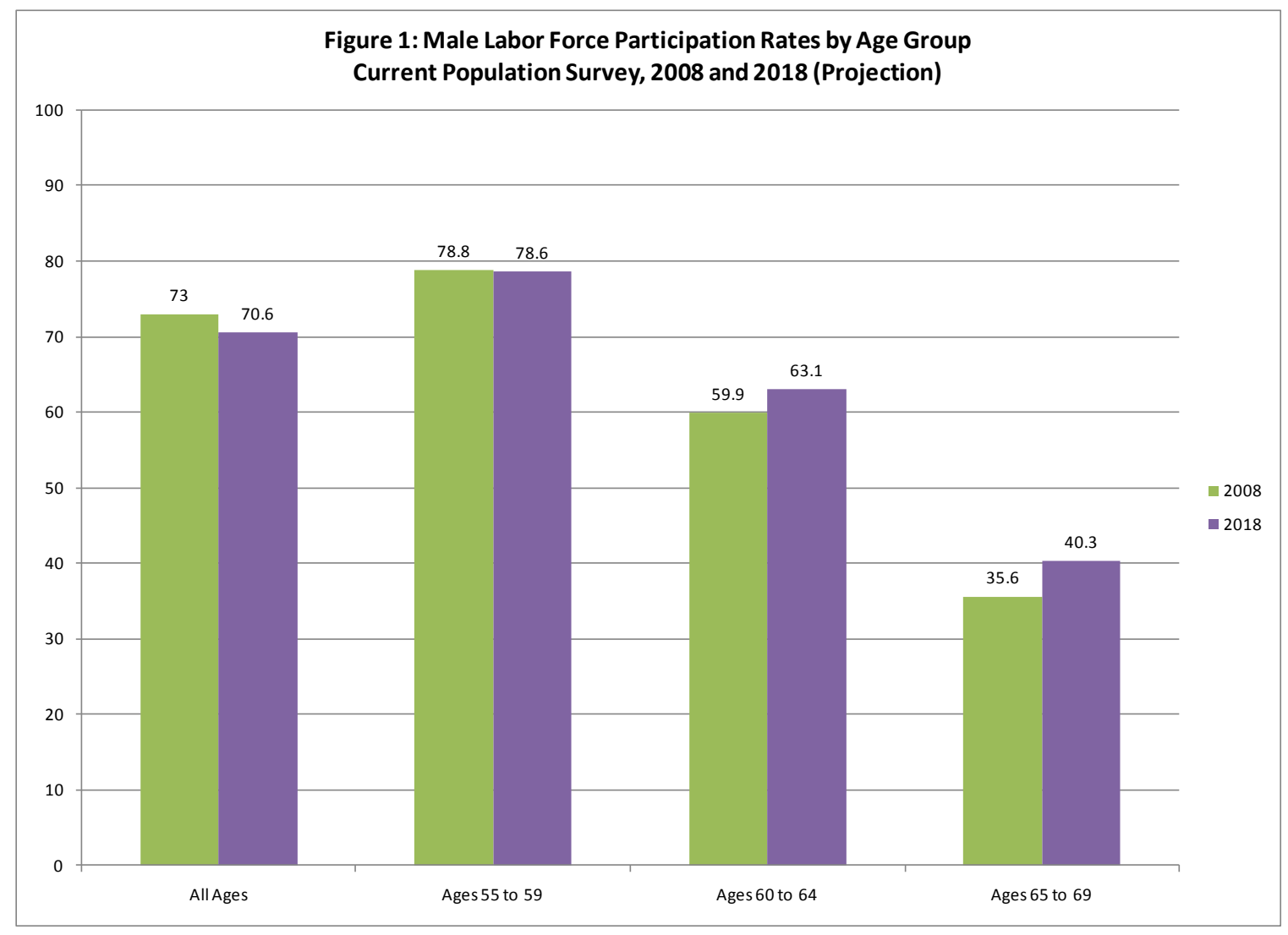

Source: Toosi (2009) 
Figure 2: Monthly Job Mobility Rates by Age in Years for Male Wage and Salary Workers Current Population Survey, 1996-2010

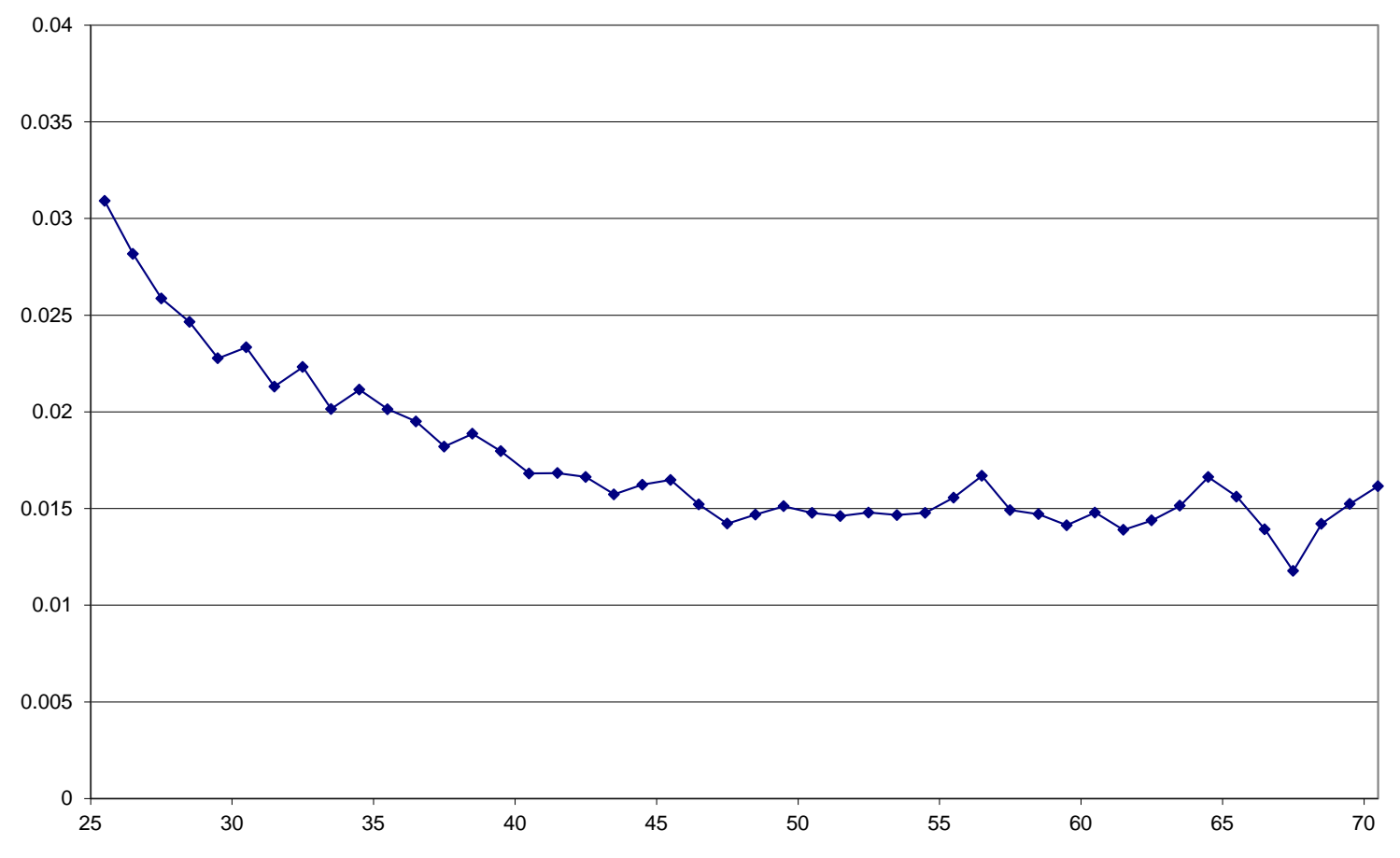


Figure 3: Job Mobility Rates by Age in 2-Month Intervals

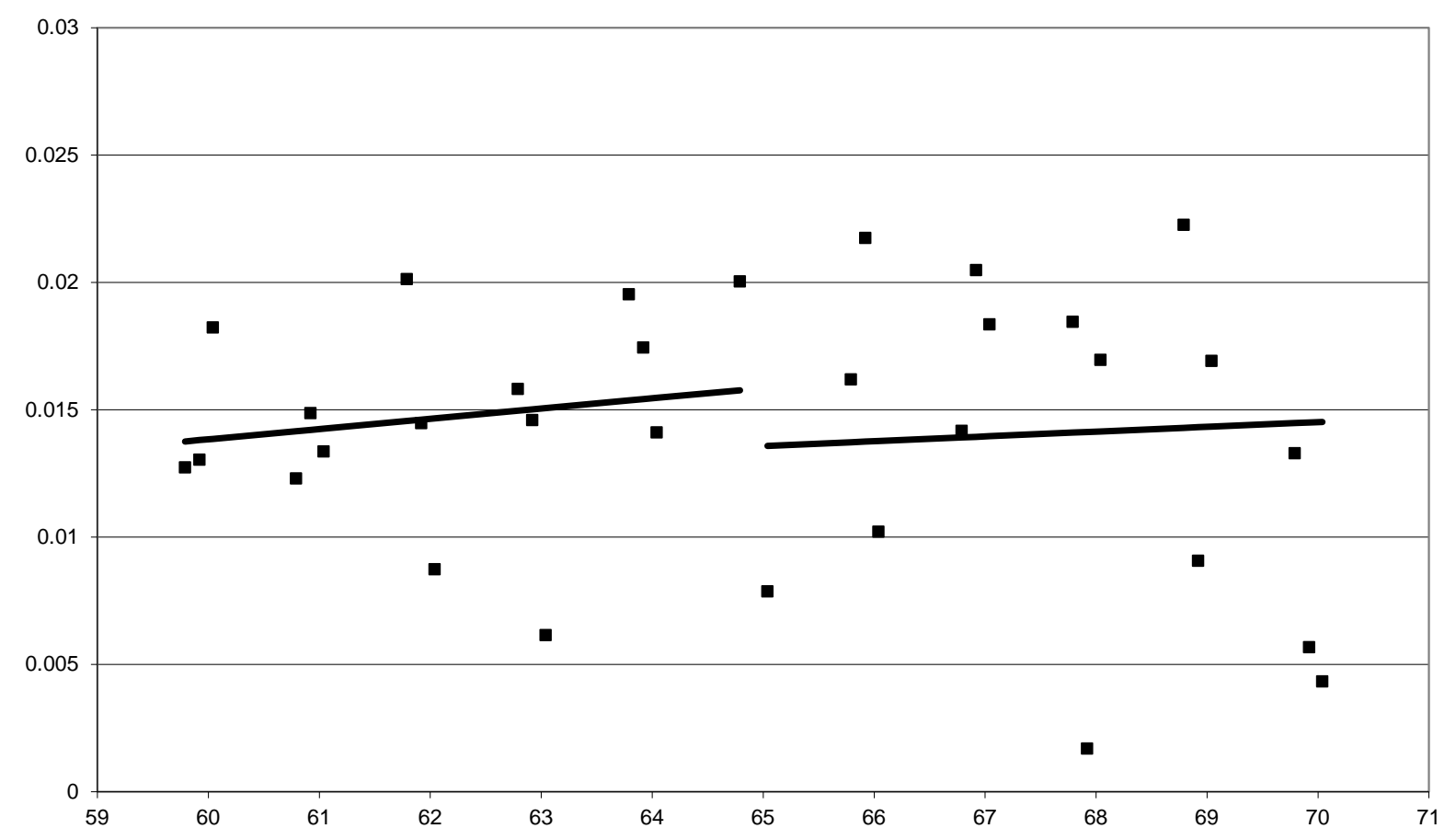


Figure 4: Job Mobility Rates by Age (Measured in Years)

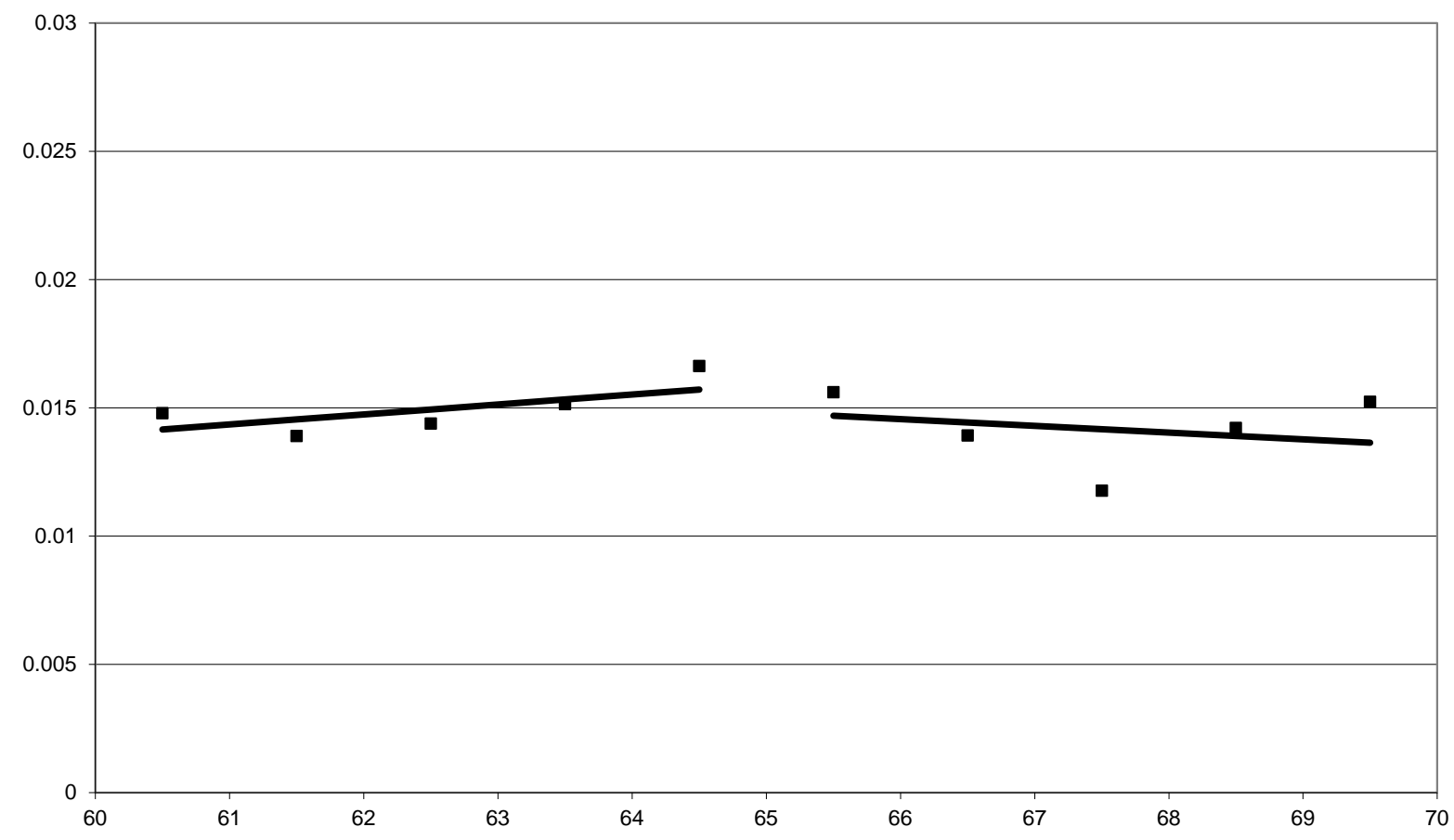


Figure 5: Confidence Interval for RDD Estimate of Job Lock by Bandwidth

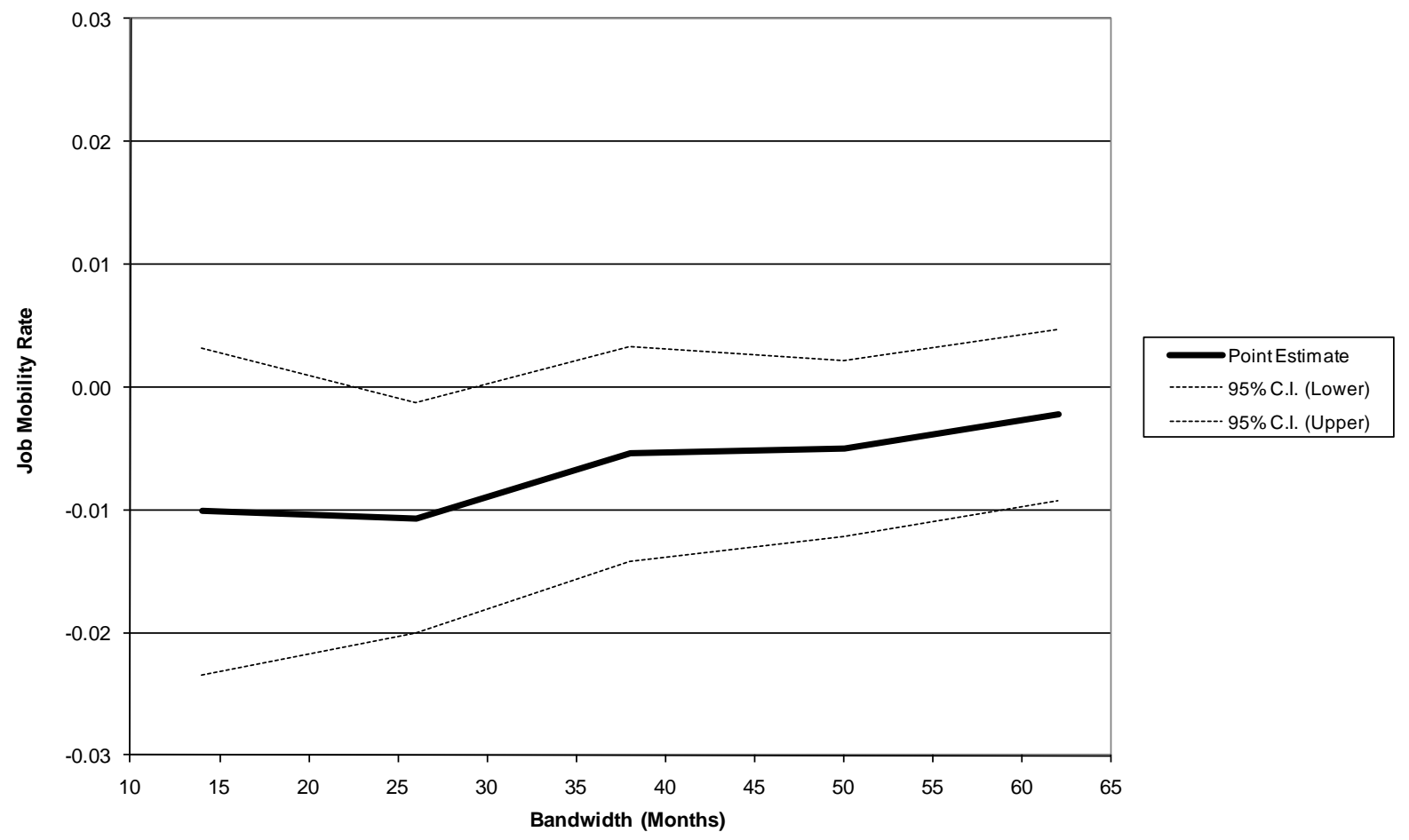


Figure 6: Confidence Interval for RDD Estimate of Job Lock by Bandwidth (Age in Years)

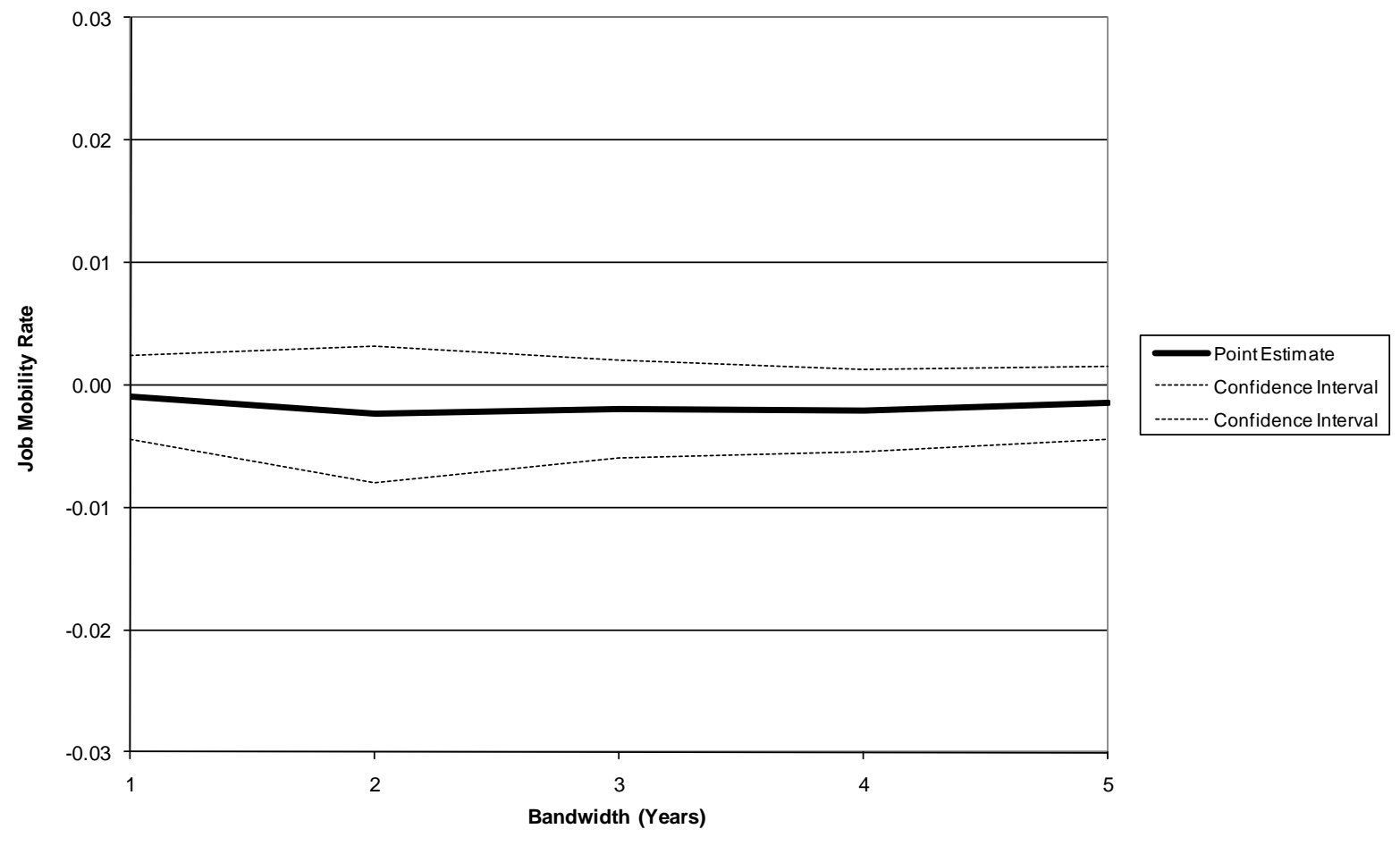


Figure 7: Weighted Sample Size by Age in 2-Month Intervals

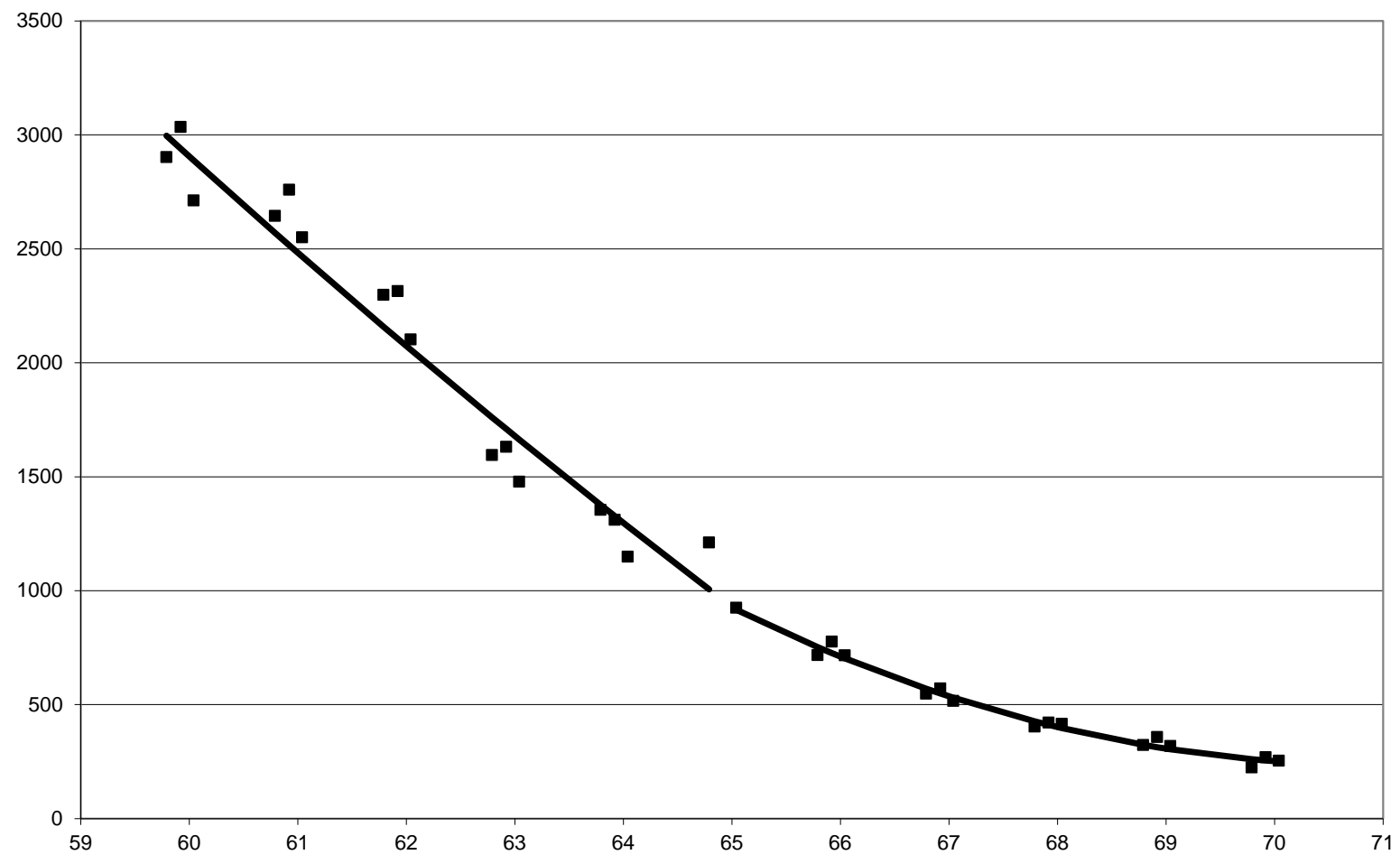


Figure 8: Job Mobility Sample Rates by Age in 2-Month Intervals

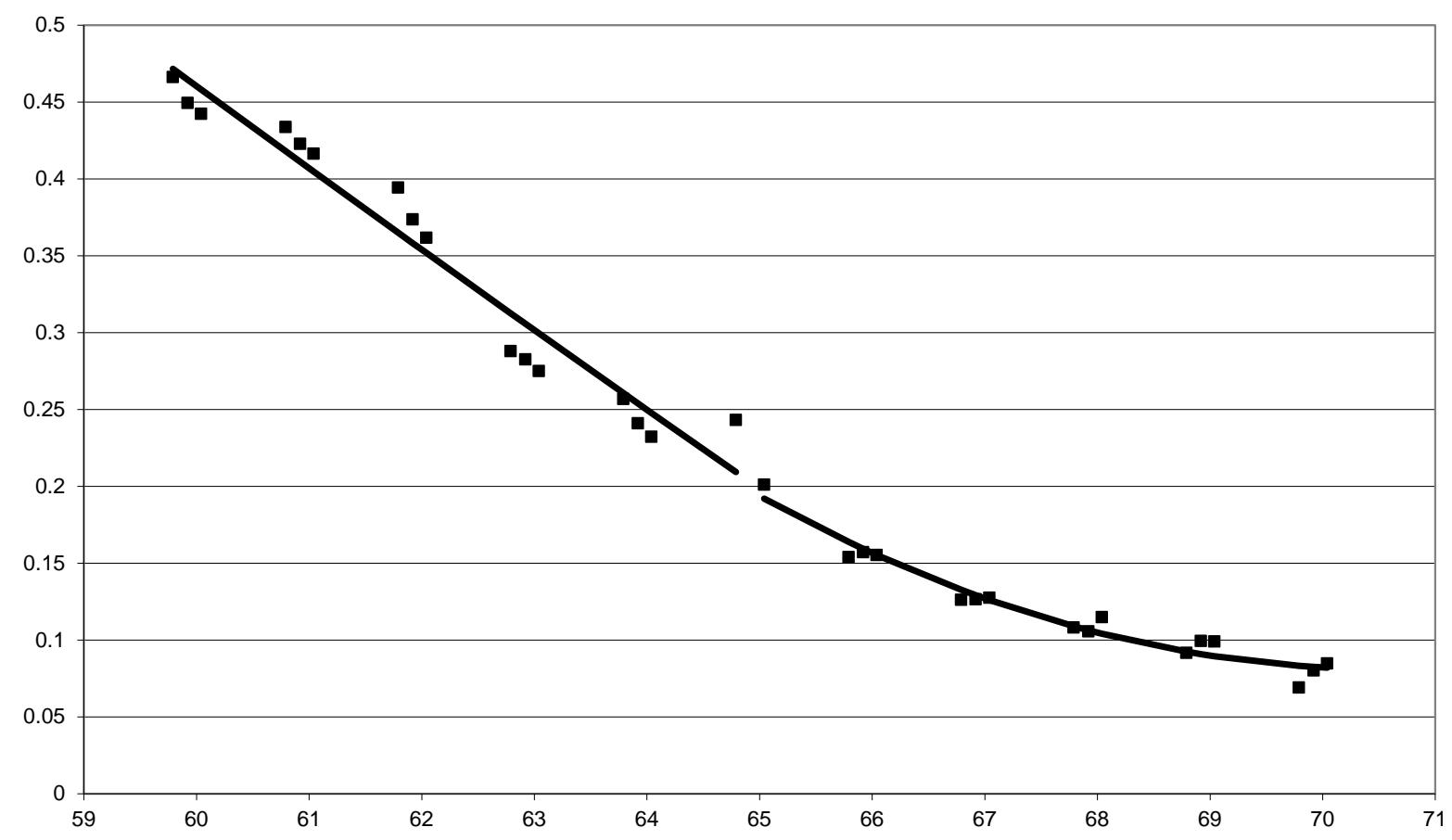


Figure 9: Minority Rates by Age in 2-Month Intervals

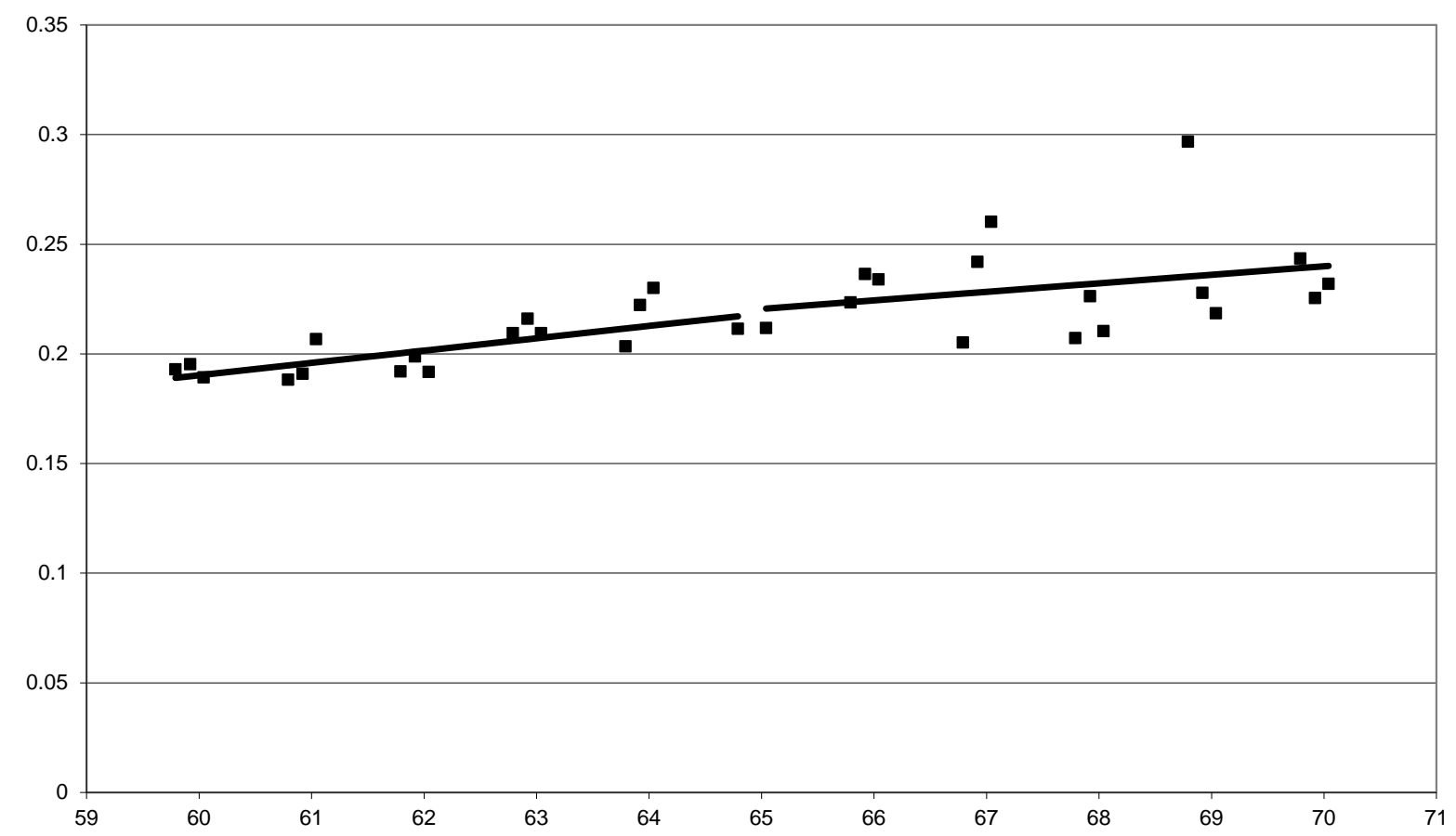


Figure 10: College Rates by Age in 2-Month Intervals

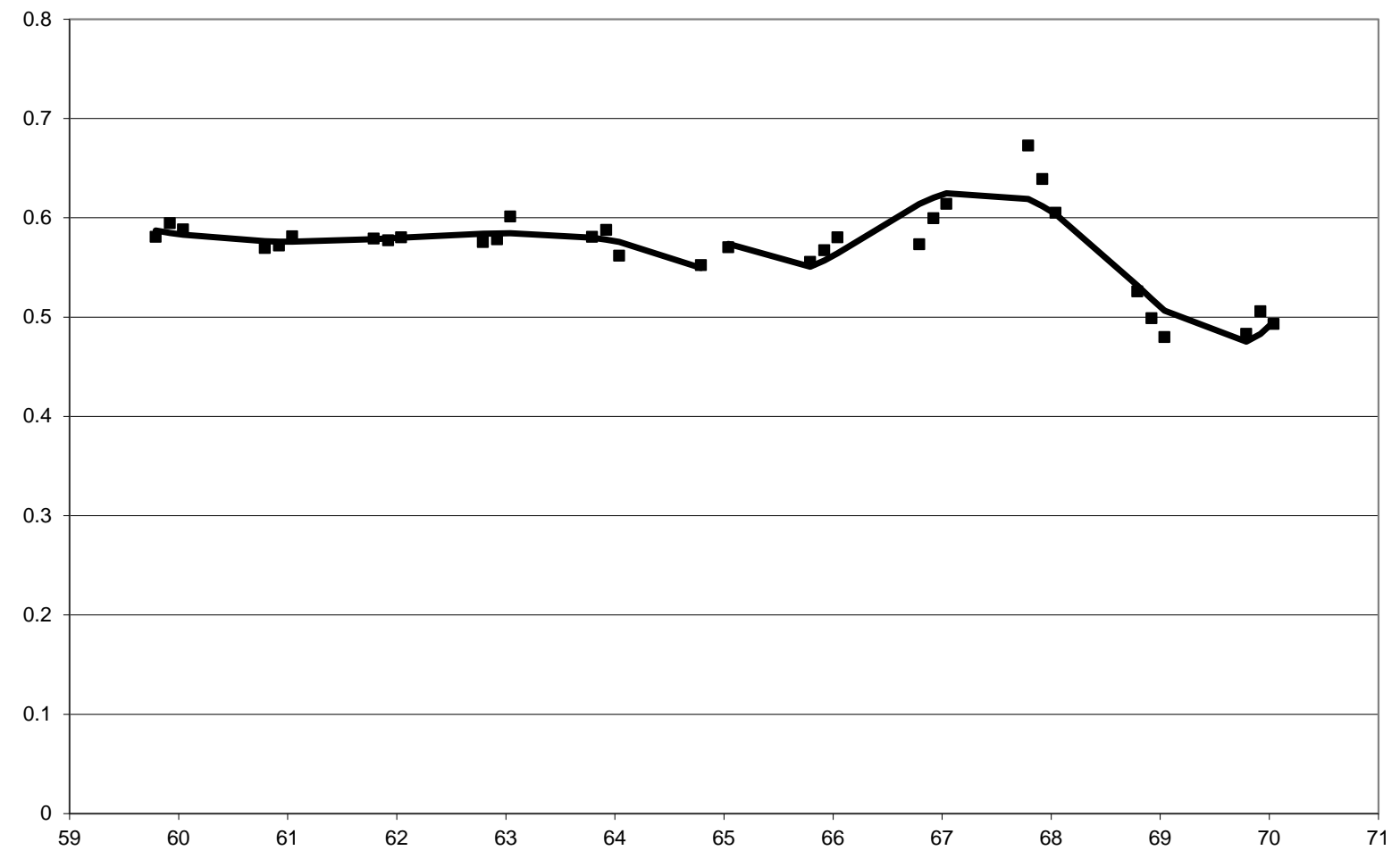


Figure 11A: Job Mobility Rates by Age in 2-Month Intervals

High Predicted Employer Provided Health Insurance Workers

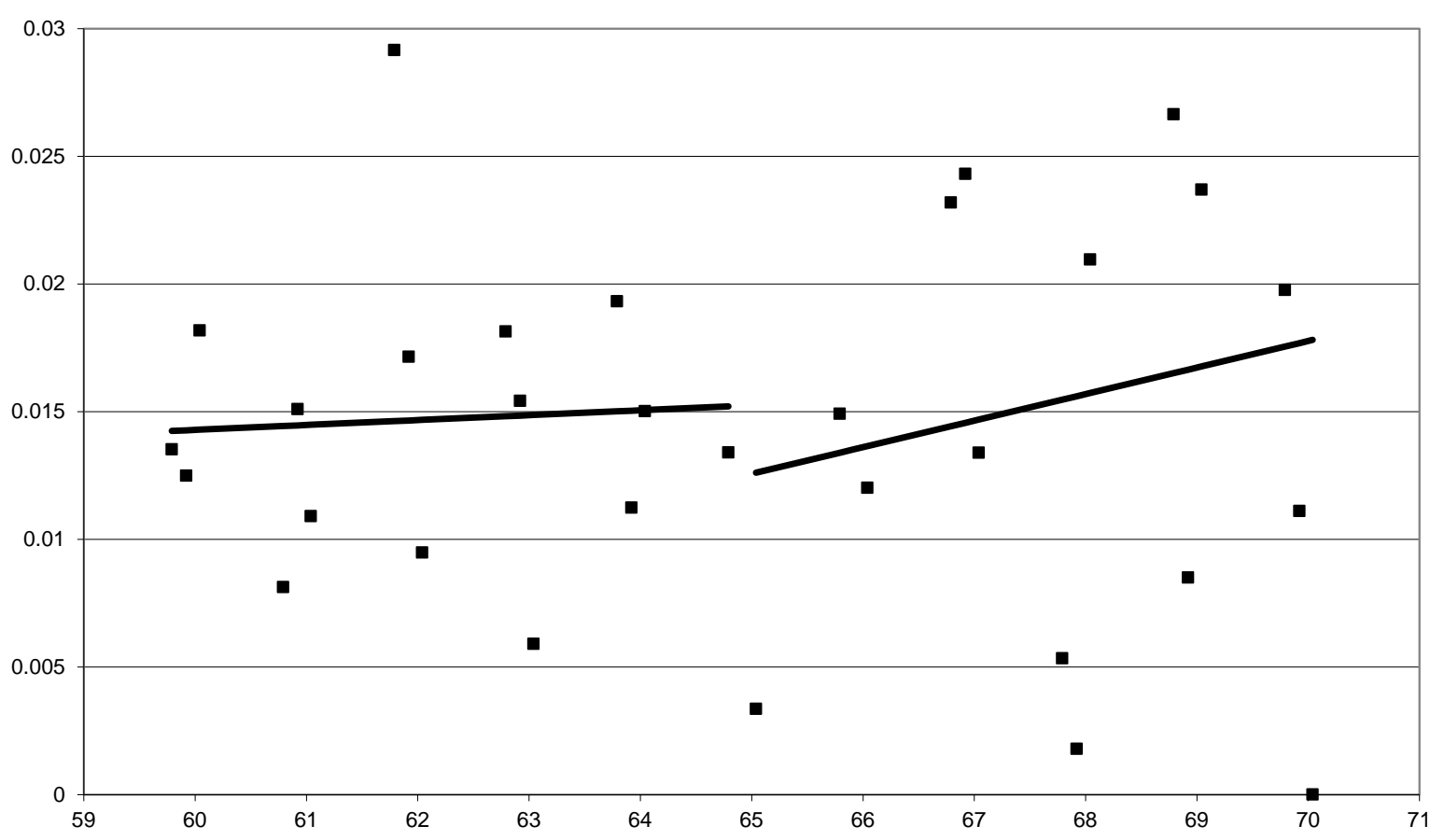

Figure 11B: Job Mobility Rates by Age in 2-Month Intervals Low Predicted Employer Provided Health Insurance Workers

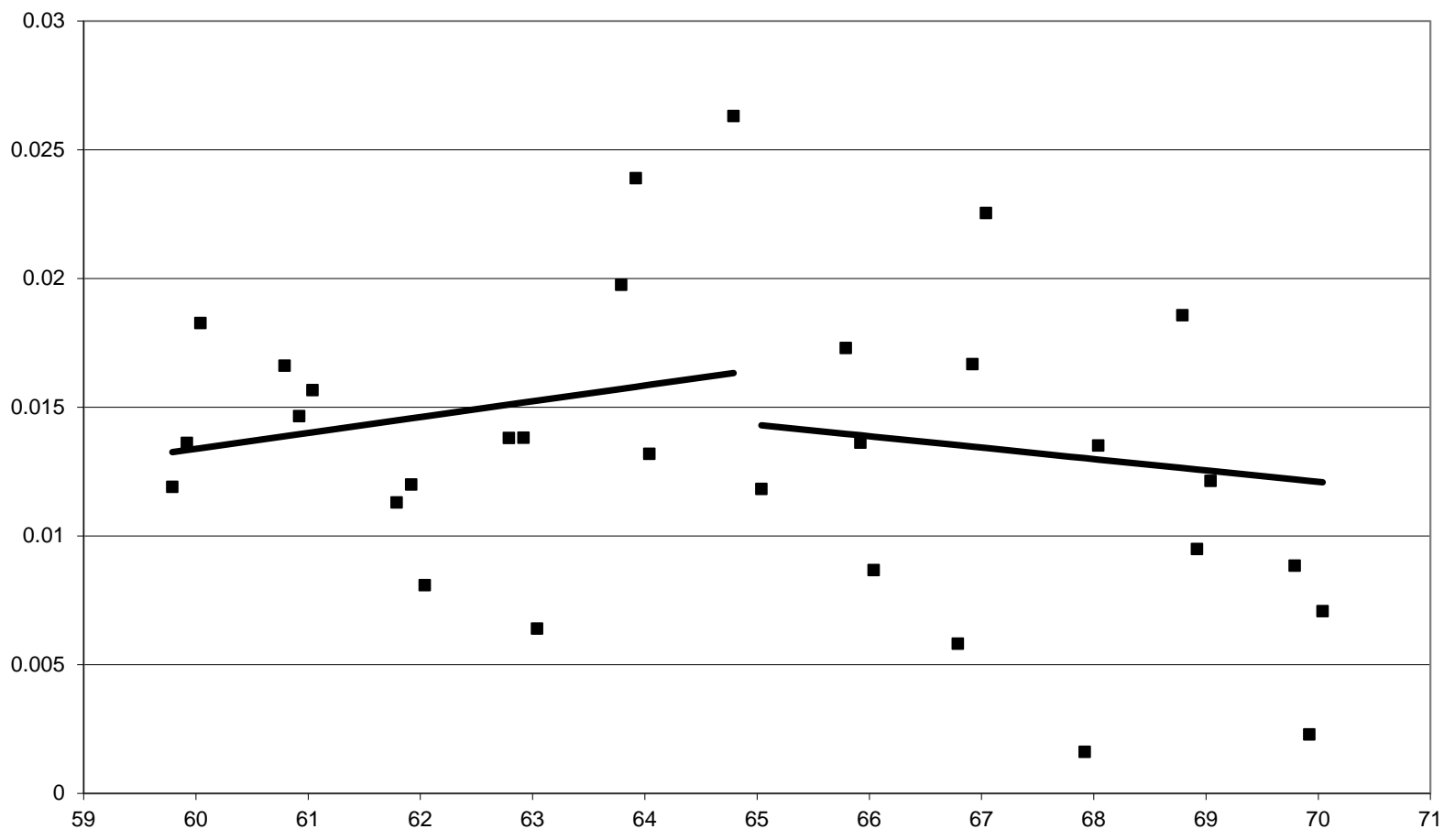


Figure 12: Job Mobility Rates by Age in 2-Month Intervals Excludes Government Workers

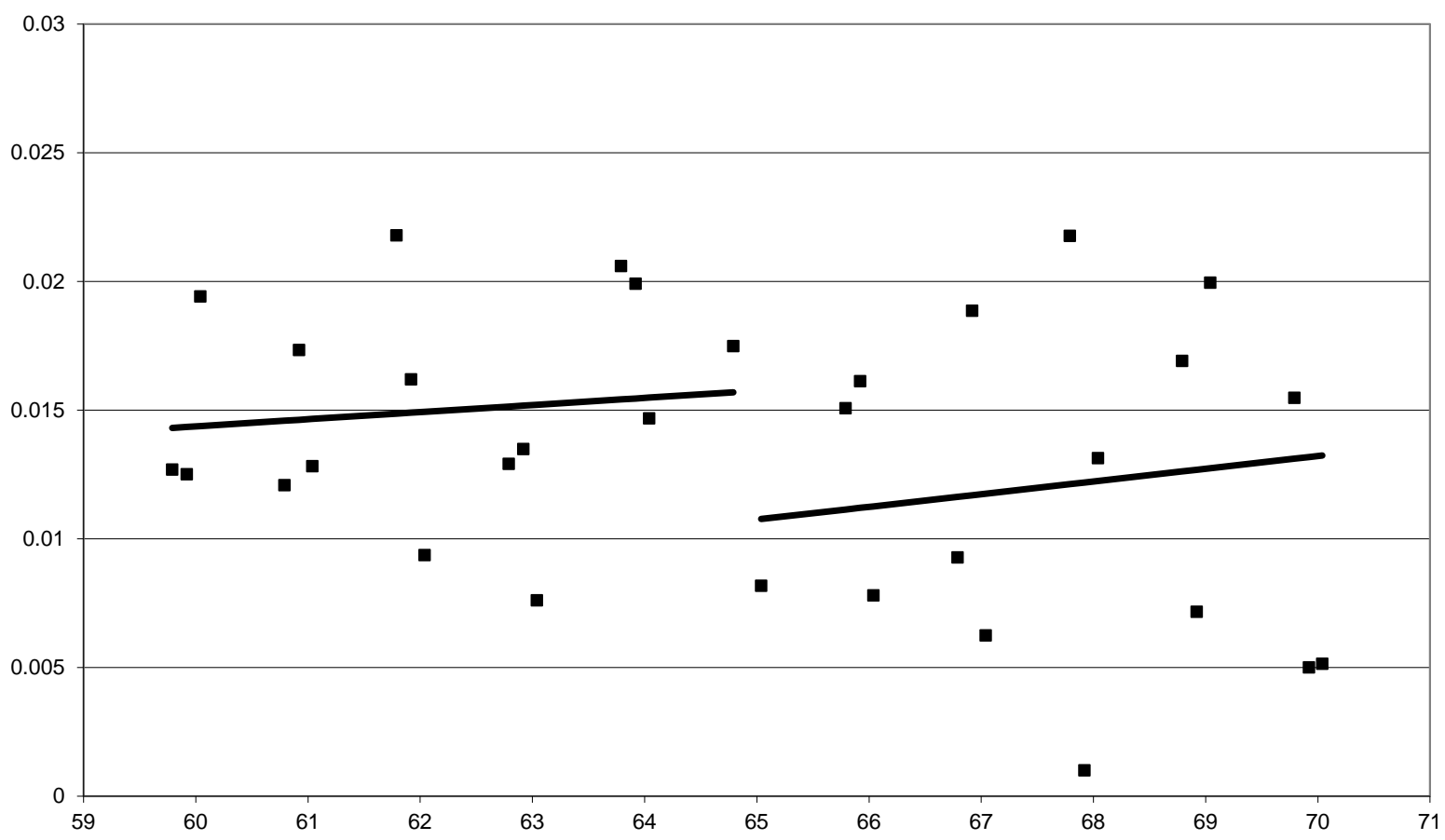


Figure 13: Retirement Rates by Age in 2-Month Intervals

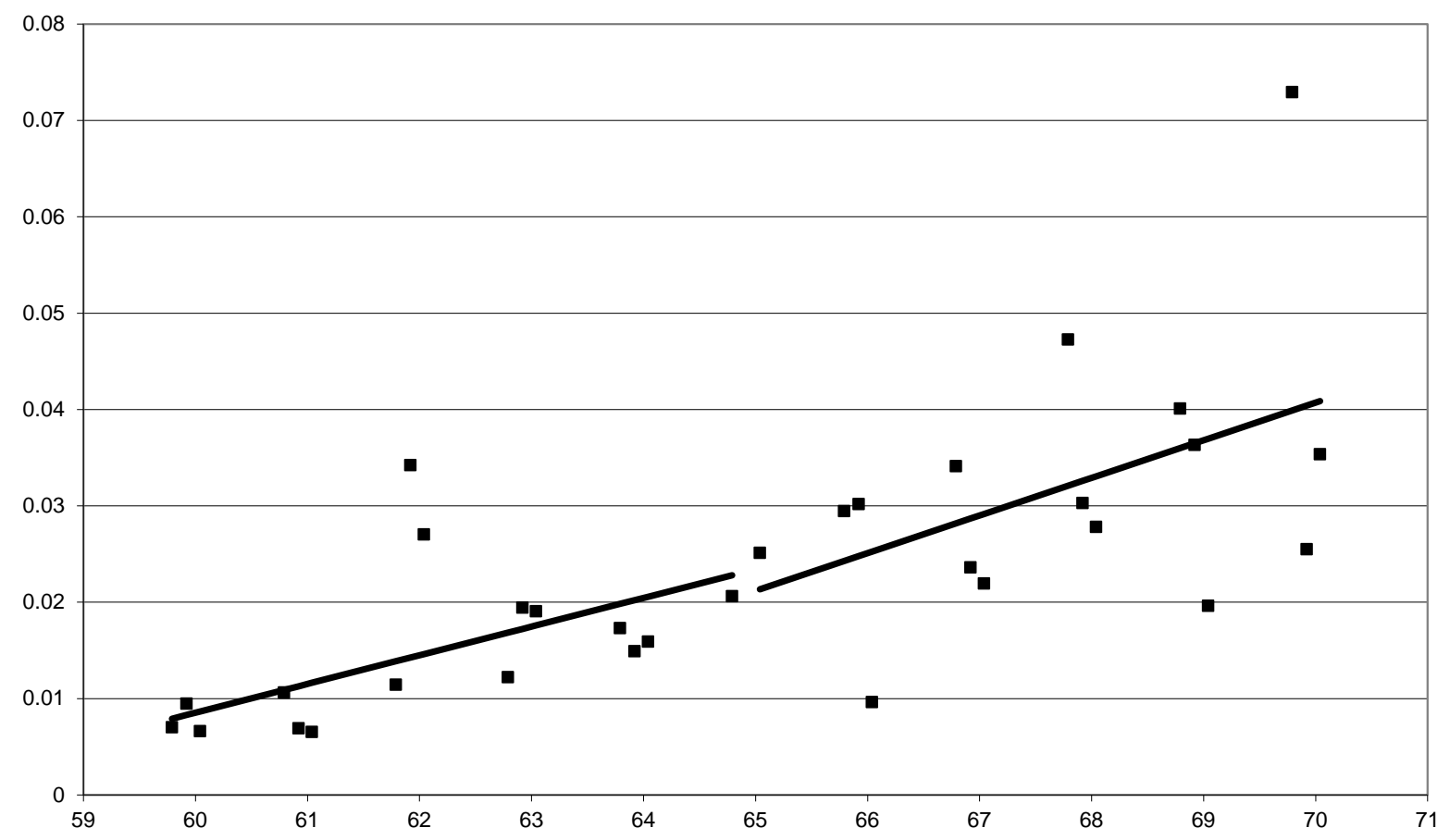


Table 1: Job Mobility Rates, Characteristics of Job Mobility, and Skill and Industry Composition of Workforce by Age Group (Ages 25-69)

\begin{tabular}{|c|c|c|c|c|c|c|c|c|c|}
\hline & $\begin{array}{c}\text { Ages } 25- \\
29 \\
\end{array}$ & $\begin{array}{c}\text { Ages } 30- \\
34 \\
\end{array}$ & $\begin{array}{c}\text { Ages } 35- \\
39 \\
\end{array}$ & $\begin{array}{c}\text { Ages } 40- \\
44\end{array}$ & $\begin{array}{c}\text { Ages 45- } \\
49\end{array}$ & $\begin{array}{c}\text { Ages } 50- \\
54\end{array}$ & $\begin{array}{c}\text { Ages 55- } \\
59 \\
\end{array}$ & $\begin{array}{c}\text { Ages 60- } \\
64 \\
\end{array}$ & $\begin{array}{c}\text { Ages 65- } \\
69 \\
\end{array}$ \\
\hline Job change rate & $2.6 \%$ & $2.2 \%$ & $1.9 \%$ & $1.7 \%$ & $1.5 \%$ & $1.5 \%$ & $1.5 \%$ & $1.5 \%$ & $1.4 \%$ \\
\hline Sample sizes & 343,285 & 379,083 & 405,291 & 416,564 & 395,960 & 337,114 & 239,538 & 123,494 & 38,683 \\
\hline \multicolumn{10}{|c|}{ Job changers experiencing: } \\
\hline Industry change & $46.7 \%$ & $42.6 \%$ & $41.3 \%$ & $39.3 \%$ & $37.6 \%$ & $35.6 \%$ & $34.0 \%$ & $33.8 \%$ & $28.2 \%$ \\
\hline Mean hours $(t+1)$ & 41.5 & 42.4 & 42.6 & 42.6 & 42.9 & 42.5 & 42.3 & 41.0 & 39.3 \\
\hline $\begin{array}{l}\text { Government/non- } \\
\text { govt. transition }\end{array}$ & $6.7 \%$ & $5.9 \%$ & $5.6 \%$ & $6.6 \%$ & $7.1 \%$ & $7.6 \%$ & $7.3 \%$ & $6.5 \%$ & $8.4 \%$ \\
\hline Sample sizes & 9,096 & 8,137 & 7,540 & 6,761 & 5,959 & 4,943 & 3,600 & 1,840 & 566 \\
\hline \multicolumn{10}{|l|}{ Worker characteristics } \\
\hline High school dropout & $11.8 \%$ & $11.4 \%$ & $10.8 \%$ & $10.0 \%$ & $9.2 \%$ & $9.2 \%$ & $10.5 \%$ & $13.0 \%$ & $15.3 \%$ \\
\hline High school graduate & $31.3 \%$ & $30.3 \%$ & $31.7 \%$ & $32.4 \%$ & $31.0 \%$ & $29.5 \%$ & $29.2 \%$ & $29.3 \%$ & $28.3 \%$ \\
\hline Some college & $27.7 \%$ & $26.1 \%$ & $25.5 \%$ & $25.9 \%$ & $26.8 \%$ & $26.7 \%$ & $25.2 \%$ & $22.9 \%$ & $20.9 \%$ \\
\hline College graduate & $29.2 \%$ & $32.2 \%$ & $32.0 \%$ & $31.7 \%$ & $33.0 \%$ & $34.6 \%$ & $35.1 \%$ & $34.8 \%$ & $35.4 \%$ \\
\hline Agriculture & $2.2 \%$ & $2.2 \%$ & $2.2 \%$ & $2.1 \%$ & $2.2 \%$ & $2.1 \%$ & $2.1 \%$ & $2.1 \%$ & $2.8 \%$ \\
\hline Construction & $12.2 \%$ & $11.6 \%$ & $11.0 \%$ & $10.3 \%$ & $9.5 \%$ & $8.4 \%$ & $7.6 \%$ & $7.3 \%$ & $6.3 \%$ \\
\hline Manufacturing & $17.0 \%$ & $19.0 \%$ & $20.8 \%$ & $22.4 \%$ & $22.5 \%$ & $22.6 \%$ & $22.3 \%$ & $21.1 \%$ & $15.5 \%$ \\
\hline Trade & $16.2 \%$ & $15.0 \%$ & $14.6 \%$ & $14.1 \%$ & $13.5 \%$ & $12.8 \%$ & $13.6 \%$ & $14.4 \%$ & $16.5 \%$ \\
\hline Transportation & $5.8 \%$ & $6.9 \%$ & $8.1 \%$ & $9.3 \%$ & $10.1 \%$ & $10.6 \%$ & $10.4 \%$ & $9.2 \%$ & $7.6 \%$ \\
\hline Information & $3.2 \%$ & $3.2 \%$ & $2.9 \%$ & $2.9 \%$ & $2.8 \%$ & $2.7 \%$ & $2.4 \%$ & $1.9 \%$ & $1.8 \%$ \\
\hline Finance & $6.3 \%$ & $6.0 \%$ & $5.9 \%$ & $5.7 \%$ & $5.4 \%$ & $5.3 \%$ & $5.7 \%$ & $6.2 \%$ & $7.1 \%$ \\
\hline Prof. Services & $12.0 \%$ & $11.6 \%$ & $10.5 \%$ & $9.3 \%$ & $8.6 \%$ & $8.1 \%$ & $8.2 \%$ & $8.8 \%$ & $10.5 \%$ \\
\hline Educational Servs. & $8.3 \%$ & $9.0 \%$ & $9.0 \%$ & $9.4 \%$ & $10.7 \%$ & $12.3 \%$ & $13.1 \%$ & $13.7 \%$ & $14.6 \%$ \\
\hline Leisure Servs. & $8.5 \%$ & $6.4 \%$ & $5.2 \%$ & $4.6 \%$ & $4.1 \%$ & $3.6 \%$ & $3.4 \%$ & $3.8 \%$ & $5.2 \%$ \\
\hline Other Servs. & $3.7 \%$ & $3.6 \%$ & $3.5 \%$ & $3.5 \%$ & $3.5 \%$ & $3.6 \%$ & $3.7 \%$ & $4.5 \%$ & $5.9 \%$ \\
\hline Public Admin. & $4.6 \%$ & $5.5 \%$ & $6.1 \%$ & $6.5 \%$ & $7.0 \%$ & $7.8 \%$ & $7.4 \%$ & $6.9 \%$ & $6.2 \%$ \\
\hline Sample sizes & 343,285 & 379,083 & 405,291 & 416,564 & 395,960 & 337,114 & 239,538 & 123,494 & 38,683 \\
\hline
\end{tabular}

Notes: (1) The sample includes male wage/salary workers with 30 or more hours worked per week in the initial survey month. (2) The job changer sample includes workers who also changed jobs from the initial survey month to the subsequent survey month. 
Table 2

Regression Discontinuity Estimates of Age 65 on Job Mobility Rates

\begin{tabular}{lccccc} 
Bandwidth & Linear & Quadratic & Cubic & Quartic & $\mathrm{N}$ \\
\hline 14 Months & -0.0101 & & & & 8,158 \\
& $(0.0068)$ & & & & \\
26 Months & -0.0107 & -0.0125 & & & 14,475 \\
& $(0.0048)$ & $(0.0075)$ & & & \\
38 Months & -0.0055 & -0.0155 & -0.0078 & & 22,570 \\
& $(0.0045)$ & $(0.0066)$ & $(0.0076)$ & & \\
50 Months & -0.0050 & -0.0103 & -0.0152 & -0.0080 & 31,738 \\
& $(0.0036)$ & $(0.0055)$ & $(0.0077)$ & $(0.0079)$ & \\
62 Months & -0.0023 & -0.0100 & -0.0133 & -0.0125 & 41,356 \\
& $(0.0035)$ & $(0.0048)$ & $(0.0066)$ & $(0.0080)$ & \\
\hline
\end{tabular}

Notes: (1) The dependent variable is whether the worker changed jobs from the initial survey month to the subsequent survey month. (2) The sample includes workers with 30 or more hours worked per week in the initial survey month. (3) Robust standard errors adjusting for clustering by age in months are in parentheses below coefficient estimates. (4) No controls are included. 
Table 3

Regression Discontinuity Estimates of Age 65 on Job Mobility Rates with Controls

\begin{tabular}{lccccc} 
Bandwidth & Linear & Quadratic & Cubic & Quartic & $\mathrm{N}$ \\
\hline 14 Months & -0.0111 & & & & 8,158 \\
& $(0.0070)$ & & & & \\
26 Months & -0.0109 & -0.0124 & & & 14,475 \\
& $(0.0050)$ & $(0.0074)$ & & & \\
38 Months & -0.0054 & -0.0155 & -0.0077 & & 22,570 \\
& $(0.0045)$ & $(0.0067)$ & $(0.0074)$ & & \\
50 Months & -0.0051 & -0.0104 & -0.0152 & -0.0081 & 31,738 \\
& $(0.0037)$ & $(0.0055)$ & $(0.0077)$ & $(0.0078)$ & \\
62 Months & -0.0023 & -0.0103 & -0.0134 & -0.0125 & 41,356 \\
& $(0.0035)$ & $(0.0049)$ & $(0.0065)$ & $(0.0080)$ & \\
\hline
\end{tabular}

Notes: (1) The dependent variable is whether the worker changed jobs from the initial survey month to the subsequent survey month. (2) The sample includes workers with 30 or more hours worked per week in the initial survey month. (3) Robust standard errors adjusting for clustering by age in months are in parentheses below coefficient estimates. (4) Controls include race, immigrant status, marital status, education, region, urbanicity, industry and year fixed effects. 
Table 4

Regression Discontinuity Estimates of Age 65 on Job Mobility Rates (Age Measured in Years)

\begin{tabular}{lccccc} 
Bandwidth & Linear & Quadratic & Cubic & Quartic & $\mathrm{N}$ \\
\hline 1 Year & -0.0010 & & & & 26,839 \\
& $(0.0017)$ & & & & \\
2 Years & -0.0025 & & & & 54,282 \\
& $(0.0028)$ & & & & \\
3 Years & -0.0019 & -0.0032 & & & \\
& $(0.0021)$ & $(0.0049)$ & & & 121,782 \\
4 Years & -0.0020 & -0.0027 & -0.0037 & & \\
& $(0.0017)$ & $(0.0032)$ & $(0.0086)$ & & 162,177 \\
5 Years & -0.0014 & -0.0034 & -0.0022 & -0.0052 & \\
& $(0.0015)$ & $(0.0026)$ & $(0.0051)$ & $(0.0153)$ & \\
\hline
\end{tabular}

Notes: (1) The dependent variable is whether the worker changed jobs from the initial survey month to the subsequent survey month. (2) The sample includes workers with 30 or more hous worked per week in the initial survey month. (3) Robust standard errors adjusting for clustering by age in years are in parentheses below coefficient estimates. (4) No controls are included. 
Table 5

Regression Discontinuity Estimates of Age 65 on Job Mobility Rates (Age Measured in Years) - Controls

\begin{tabular}{lccccc} 
Bandwidth & Linear & Quadratic & Cubic & Quartic & $\mathrm{N}$ \\
\hline 1 Year & -0.0010 & & & & 26,839 \\
& $(0.0017)$ & & & & \\
2 Years & -0.0024 & & & & 54,282 \\
& $(0.0028)$ & & & & \\
3 Years & -0.0020 & -0.0032 & & & \\
& $(0.0021)$ & $(0.0049)$ & & & 121,782 \\
4 Years & -0.0021 & -0.0026 & -0.0035 & & \\
& $(0.0017)$ & $(0.0032)$ & $(0.0086)$ & & 162,177 \\
5 Years & -0.0015 & -0.0033 & -0.0020 & -0.0052 & \\
& $(0.0015)$ & $(0.0026)$ & $(0.0051)$ & $(0.0153)$ & \\
\hline
\end{tabular}

Notes: (1) The dependent variable is whether the worker changed jobs from the initial survey month to the subsequent survey month. (2) The sample includes workers with 30 or more hous worked per week in the initial survey month. (3) Robust standard errors adjusting for clustering by age in years are in parentheses below coefficient estimates. (4) Controls include race, immigrant status, marital status, education, region, urbanicity, industry and year fixed effects. 
Table 6

Regression Discontinuity Estimates of Age 65 on Job Mobility Rates

Expanded Age Range (Ages 55-70)

\begin{tabular}{lccccc} 
Bandwidth & Linear & Quadratic & Cubic & Quartic & $\mathrm{N}$ \\
\hline 74 Months & -0.0006 & -0.0092 & -0.0118 & -0.0143 & 51,747 \\
& $(0.0033)$ & $(0.0043)$ & $(0.0060)$ & $(0.0075)$ & \\
86 Months & -0.0007 & -0.0060 & -0.0132 & -0.0121 & 62,793 \\
& $(0.0031)$ & $(0.0042)$ & $(0.0055)$ & $(0.0068)$ & \\
98 Months & -0.0007 & -0.0046 & -0.0113 & -0.0143 & 74,794 \\
& $(0.0029)$ & $(0.0041)$ & $(0.0052)$ & $(0.0066)$ & \\
110 Months & 0.0007 & -0.0051 & -0.0083 & -0.0152 & 88,244 \\
& $(0.0028)$ & $(0.0038)$ & $(0.0049)$ & $(0.0062)$ & \\
122 Months & 0.0009 & -0.0043 & -0.0083 & -0.0131 & 92,934 \\
& $(0.0027)$ & $(0.0038)$ & $(0.0047)$ & $(0.0059)$ & \\
\hline
\end{tabular}

Notes: (1) The dependent variable is whether the worker changed jobs from the initial survey month to the subsequent survey month. (2) The sample includes workers with 30 or more hours worked per week in the initial survey month. (3) Robust standard errors adjusting for clustering by age in months are in parentheses below coefficient estimates. (4) Controls include race, immigrant status, marital status, education, region, urbanicity, industry and year fixed effects. 
Table 7

Regression Discontinuity Estimates of Age 65 on Job Mobility Rates (Age Measured in Years)

Expanded Age Range (Ages 55-74)

\begin{tabular}{lccccc} 
Bandwidth & Linear & Quadratic & Cubic & Quartic & $\mathrm{N}$ \\
\hline 6 Years & -0.0016 & -0.0022 & -0.0044 & 0.0004 & 205,666 \\
& $(0.0014)$ & $(0.0022)$ & $(0.0039)$ & $(0.0084)$ & \\
7 Years & -0.0015 & -0.0021 & -0.0032 & -0.0047 & 252,409 \\
& $(0.0013)$ & $(0.0020)$ & $(0.0032)$ & $(0.0060)$ & \\
8 Years & -0.0011 & -0.0022 & -0.0027 & -0.0042 & 302,470 \\
& $(0.0012)$ & $(0.0018)$ & $(0.0028)$ & $(0.0048)$ & \\
9 Years & 0.0001 & -0.0032 & -0.0015 & -0.0048 & 357,038 \\
& $(0.0011)$ & $(0.0017)$ & $(0.0025)$ & $(0.0040)$ & \\
10 Years & 0.0003 & -0.0024 & -0.0032 & -0.0012 & 415,994 \\
& $(0.0011)$ & $(0.0016)$ & $(0.0023)$ & $(0.0035)$ & \\
\hline
\end{tabular}

Notes: (1) The dependent variable is whether the worker changed jobs from the initial survey month to the subsequent survey month. (2) The sample includes workers with 30 or more hous worked per week in the initial survey month. (3) Robust standard errors adjusting for clustering by age in years are in parentheses below coefficient estimates. (4) Controls include race, immigrant status, marital status, education, region, urbanicity, industry and year fixed effects. 
Table 8

Regression Discontinuity Estimates of Age 65 on Retirement Rates

\begin{tabular}{lccccc} 
Bandwidth & Linear & Quadratic & Cubic & Quartic & $\mathrm{N}$ \\
\hline 14 Months & 0.0070 & & & & 8,466 \\
& $(0.0057)$ & & & & \\
26 Months & 0.0047 & 0.0066 & & & 15,025 \\
& $(0.0052)$ & $(0.0057)$ & & & \\
38 Months & 0.0052 & 0.0072 & 0.0020 & & 23,484 \\
& $(0.0058)$ & $(0.0058)$ & $(0.0062)$ & & \\
50 Months & 0.0005 & 0.0097 & 0.0059 & -0.0003 & 32,910 \\
& $(0.0047)$ & $(0.0072)$ & $(0.0057)$ & $(0.0067)$ & \\
62 Months & -0.0019 & 0.0068 & 0.0112 & 0.0011 & 42,822 \\
& $(0.0048)$ & $(0.0060)$ & $(0.0065)$ & $(0.0061)$ & \\
\hline
\end{tabular}

Notes: (1) The dependent variable is whether the worker retired between the initial survey month and the subsequent survey month. (2) The sample includes workers with 30 or more hours worked per week in the initial survey month. (3) Robust standard errors adjusting for clustering by age in months are in parentheses below coefficient estimates. (4)

Controls include race, immigrant status, marital status, education, region, urbanicity, industry and year fixed effects. 
Table 9

Regression Discontinuity Estimates of Age 65 on Weekly Hours Worked

\begin{tabular}{lccccc} 
Bandwidth & Linear & Quadratic & Cubic & Quartic & $\mathrm{N}$ \\
\hline 14 Months & 0.1626 & & & & 8,160 \\
& $(0.2102)$ & & & & \\
26 Months & -0.0438 & 0.1648 & & & 14,481 \\
& $(0.3317)$ & $(0.2606)$ & & & \\
38 Months & -0.4180 & 0.2379 & 0.0772 & & 22,577 \\
& $(0.3171)$ & $(0.2819)$ & $(0.2675)$ & & \\
50 Months & -0.6769 & -0.0143 & 0.3926 & -0.3464 & 31,745 \\
& $(0.3725)$ & $(0.2618)$ & $(0.2918)$ & $(0.3027)$ & \\
62 Months & -0.6814 & -0.2470 & 0.2904 & 0.2061 & 41,366 \\
& $(0.3201)$ & $(0.3310)$ & $(0.2805)$ & $(0.2573)$ & \\
\hline
\end{tabular}

Notes: (1) The dependent variable is hours worked per week among workers in the subsequent survey month. (2) The sample includes workers with 30 or more hours worked per week in the initial survey month. (3) Robust standard errors adjusting for clustering by age in months are in parentheses below coefficient estimates. (4) Controls include race, immigrant status, marital status, education, region, urbanicity, industry and year fixed effects. 
Table 10

Regression Discontinuity Estimates for Job Mobility Rates at Different Age Cutoffs

\begin{tabular}{cccrc} 
& \multicolumn{4}{c}{ Linear Specification (Bandwidth=62 Months) } \\
Cutoff Age & Coefficient & Std. Err. & t-stat & $\mathrm{N}$ \\
\hline 60 & 0.0009 & $(0.0021)$ & 0.44 & 82,043 \\
61 & 0.0001 & $(0.0026)$ & 0.04 & 80,036 \\
62 & -0.0042 & $(0.0026)$ & -1.63 & 69,050 \\
63 & -0.0014 & $(0.0032)$ & -0.45 & 59,459 \\
64 & 0.0010 & $(0.0032)$ & 0.31 & 50,205 \\
65 & -0.0023 & $(0.0035)$ & -0.65 & 41,356 \\
66 & 0.0007 & $(0.0033)$ & 0.22 & 33,442 \\
67 & 0.0036 & $(0.0035)$ & 1.01 & 25,961 \\
68 & -0.0024 & $(0.0035)$ & -0.67 & 19,706 \\
69 & -0.0038 & $(0.0041)$ & -0.91 & 15,436 \\
70 & -0.0070 & $(0.0045)$ & -1.55 & 11,919 \\
\hline
\end{tabular}

Notes: (1) The dependent variable is whether the worker changed jobs from the initial survey month to the subsequent survey month. (2) The sample includes workers with 30 or more hours worked per week in the initial survey month. (3) Robust standard errors adjusting for clustering by age in months are in parentheses below coefficient estimates. (4) Controls include race, immigrant status, marital status, education, region, urbanicity, industry and year fixed effects. 